\title{
LA INFLACIÓN EN EL IMPERIO ROMANO \\ DE DIOCLECIANO A TEODOSIO
}

\section{INFLATION IN THE ROMAN EMPIRE FROM DIOCLETIAN TO THEODOSIUS}

Alberto GonZÁlez García Universidad Complutense de Madrid

\begin{abstract}
Resumen: Este trabajo pretende esclarecer y explicar la política monetaria romana en el marco de las transformaciones operadas durante el siglo IV a partir del modelo teórico de la Escuela Austríaca de Economía. Mediante el estudio de las mutaciones monetarias, sus causas y sus consecuencias se pretende contribuir a un mejor entendimiento de la política fiscal y la dinámica social de la época, a través de dos objetivos específicos: $a$ ) la comprensión de los conceptos básicos de dinero e inflación, y b) la comprensión de la política monetaria y del proceso inflacionario a lo largo del período especificado, sus causas y consecuencias, así como su relación con el contexto sociohistórico.
\end{abstract}

Palabras clave: Inflación, política monetaria, Imperio Romano Tardío.

\begin{abstract}
This paper aims to clarify and explain the Roman monetary policy in the context of transformations in the Fourth Century through the theoretical model of the Austrian School of Economics. By studying monetary mutations, its causes and its consequences, it is intended to contribute to a better comprehension of fiscal policy and social dynamics of the period, by two specific objectives: $a$ ) understanding the basic concepts of money and inflation, and $b$ ) understanding of monetary policy and the inflationary process during the specified period, its causes and consequences, as well as their relationship with socio-historical context.
\end{abstract}

Keywords: Inflation, monetary policy, Later Roman Empire.

Si vero Italici seu Romani tales mutationes finaliter fecerunt, sicut videtur ex quadam prava moneta veteri quae quandoque reperitur in campis, hoc fuit forte una de causis quare eorum nobile dominium devenit ad nihilum. Sic igitur patet quod istae mutationes tam malae sunt quod de natura sua non sunt aliquatenus permittendae.

Nicolás de Oresme (c. 1350). ${ }^{1}$

\section{BASES ECONÓMICAS: DINERO E INFLACIÓN}

Consideramos que la incomprensión del fenómeno inflacionario -sus causas y consecuencias- ha determinado muchos los problemas de análisis y discernimiento de la política monetaria del Dominado, así como la oscuridad y el fárrago imperantes en sus debates. Por ello nos planteamos ante todo los propios conceptos de dinero e inflación.

\footnotetext{
1 De origine, natura, iure et mutationibus monetarum, 18.
} 
La escuela económica monetarista, de extraordinario predicamento entre los historiadores económicos, se basa en una concepción exclusivamente cuantitativa del dinero. ${ }^{2}$ Ahora bien, resulta evidente que no todos los bienes pueden emplearse como dinero y que la moneda es mucho más que un testigo presencial, puesto que refleja un poder político y unas circunstancias históricas concretas, e influye más que notablemente en éstas. ${ }^{3}$

La Escuela Austríaca de Economía ha sido la única capaz de desarrollar una teoría monetaria solvente, ${ }^{4}$ basada en el aspecto cualitativo del dinero. ${ }^{5}$ Carl Menger lo definió como aquel bien con unas características determinadas que permiten emplearlo como depósito de valor, y en consecuencia como medio de intercambio y unidad de cuenta. ${ }^{6}$ Debido a su perdurabilidad, inalterabilidad y escasez, los metales preciosos han sido durante milenios el dinero por excelencia, mucho antes incluso de la invención de la moneda. ${ }^{7}$ De tal modo, se halla sujeto, al igual que los demás bienes y servicios, a las leyes de la oferta y la demanda, y a factores tales como la oferta futura esperada, la calidad y toda suerte de factores psicológicos complejos y subjetivos, que, simple y llanamente, no pueden ser cuantificados. ${ }^{8}$ Es por ello, por ejemplo, que el dinero puede devaluarse sin que se incremente la cantidad circulante.

Distinguimos tres tipos de dinero: el natural, el fiduciario y el fiat. Este último es el actual papel-moneda. ${ }^{9}$ El fiduciario son las letras de cambio y los antiguos billetes de banco, fideicomisos, por lo general al portador, en los que el emisor garantiza el cobro de una determinada cantidad en dinero natural.

Hemos de aclarar que el valor nominal de la moneda metálica es siempre superior al intrínseco. De no ser así, la acuñación sería antieconómica y no se produciría. Esta diferencia es el llamado señoraje, el ingreso bruto que recibe la autoridad emisora -en este caso el Estado romano-, con

2 Se formaliza en la célebre ecuación de Fisher (MV = PQ), según la cual el nivel general de precios $(\mathrm{P})$ es igual a la cantidad de dinero (M) multiplicada por su "velocidad de circulación" (V) y dividida por el volumen de transacciones (Q), cf. I. FISHER, The Purchasing Power of Money: Its Determination and Relation to Credit Interest and Crises, Nueva York, 1916, pp. 24-5. Así, un incremento de la oferta monetaria tan sólo provoca una subida de los precios en idéntica proporción, de modo que sus posibles efectos adversos sobre la producción, el consumo o el empleo deberían neutralizarse a largo plazo. Sobre los planteamientos cuantitativos, $c f$. J. SCHUMPETER, Historia del análisis económico, Barcelona, 1994, pp. 1088 ss.

3 Para una crítica del cuantitativismo, véase J. HUERTA DE SOTO, Dinero, crédito bancario y ciclos económicos, Madrid, 1998, pp. 399 ss.

4 Como vemos, la cuantitativa es limitada, y la marxista simplemente inexistente. Sobre el pobre resultado de quienes tratan de rastrear esta última, $c f$. V. MARTÍN MARTÍN, "A la búsqueda de una teoría monetaria en Marx", Información Comercial Española: Revista de economía 845 (2008), pp. 25-44.

5 Para esta sucinta exposición, seguimos a L. von MISES, The Theory of Money and Credit, New Haven, 1953, y M. ROTHBARD, "La teoría austríaca del dinero", en Libertas, 13 (1990), pp. 23-53.

6 C. MENGER, “On the Origins of Money”, Economic Journal, 2 (1892), pp. 239-55. Ya Aristóteles desarrolló la primera teoría monetaria cataláctica, $c f$. J. SCHUMPETER, Historia ..., pp. 99-101.

7 Para apreciar cómo la teoría de Menger se ajusta por completo a la evidencia de las modernas investigaciones sobre los orígenes de la moneda, $c f$. J.H. KROLL, "The Monetary Use of Weighted Bullion in Archaic Greece" en W. V. HARRIS (ed.), The Monetary Systems of the Greeks and Romans, Oxford, 2008, pp. 12-37, y G. LE RIDER, La naissance de la monnaie, París, 2001.

${ }^{8}$ Hasta llegar a extremos insospechados: en un pasaje célebre, el filósofo Epicteto (55-135) narraba la aleccionadora historia de un hombre que prefirió aceptar una moneda de Trajano a otra de Nerón, a pesar del mayor valor de esta última, debido a la baja catadura moral del Enobarbo (Disertaciones 5, 17).

9 Resultado de un decreto gubernamental que proclama "hágase el dinero" (fiat pecunia!) sin respaldarlo con activo alguno, imponiendo su circulación. 
el cual cubre sus costes de acuñación y obtiene un beneficio que le incentiva a producir moneda. ${ }^{10}$ Es por ello, y no por "fiduciarización" alguna, que la jurisprudencia romana la definía como un pretium y no como merx. ${ }^{11}$

El señoraje es el precio que paga el usuario por las ventajas que supone el disponer de un medio de intercambio estándar cuyo peso y ley están garantizados por el cuño, evitando la necesidad de pesar y ensayar el metal con cada transacción, operaciones siempre inexactas con los medios de aquella época, ${ }^{12}$ que para colmo no sofocaban del todo la incertidumbre de haber sido objeto de engaño o fraude. Y puesto que una acuñación tradicional a martillo como la romana implica la utilización del mismo procedimiento para todas las monedas, con independencia de su contenido metálico y tamaño, el coste unitario de cada pieza se halla en proporción inversa a su valor, y es preciso que el señoraje sea mayor en el vellón que en la plata o el oro. El problema llega, naturalmente, cuando la autoridad pretende cobrar un precio abusivo emitiendo una moneda cuyo valor nominal supera en exceso al intrínseco.

Creemos que el desconocimiento de estas mínimas bases económicas es el que ha llevado a considerar "fiduciaria" la moneda imperial, ${ }^{13} \mathrm{o}$ a sostener que circulaba únicamente por su valor metálico. ${ }^{14}$ Aclarados los tipos de dinero, podemos descartar tales dislates: no era fiduciaria, porque no era un contrato de fiducia que garantizara su convertibilidad en metal precioso, y no circulaba al peso porque, de ser así, ningún Estado se hubiera tomado la costosísima molestia de acuñar moneda alguna.

Con respecto a la inflación, para la Escuela Austriaca no es un simple aumento en el nivel general de precios, sino el incremento indebido de la oferta monetaria (dinero y crédito) en relación a la demanda (los bienes y servicios existentes), ${ }^{15}$ es decir, un descenso del valor de cada unidad monetaria por razones exógenas al mercado. En suma, un fenómeno estrictamente monetario, que en el caso del numerario podía producirse por tres medios, todos los cuales se dieron en el siglo IV: a) la disminución del peso, $b$ ) la disminución de la ley y $c$ ) los cambios de valor puramente nominales. ${ }^{16}$

10 También traducido como "señoreaje" (francés medieval: "seignorage"), en sentido lato está compuesto de tres partes: el coste de acuñación o brassage, el beneficio neto del acuñador y el señoraje propiamente dicho, en su sentido más estricto, es decir, el impuesto que percibían las autoridades estatales de las casas de moneda, que en la Edad Media solían ser negocios privados, y por lo común trabajaban por cuenta ajena, es decir, acuñaban el metal de particulares. Sobre el señoraje, $c f$. A. SMITH, An Inquiry into the Nature and Causes of the Wealth of Nations, Londres, 1776, I, 5, 39 y IV, 6, 15-32, y D. RICARDO, "Reply to Mr. Bosanquet's Practical Observation on the Report of the Bullion Committee", en J.R. MCCULLOCH (ed.), The Works of David Ricardo, Londres, 1846, pp. 345-7.

$11 C f$. E. LO CASCIO, "How Did the Romans View their Coinage and its Function?", en C. E. KING \& D. G. WIGG (eds.), Coin Finds and Coin Use in the Roman World, Berlín, 1996, p. 271-287.

12 Aunque sea más del mil años posterior al período que nos ocupa, e incluso teniendo en cuenta los avances técnicos de la Edad Moderna, nos podemos hacer una idea de los medios de los que podían disponer a este efecto en J. de ARFE, Quilatador de la plata, oro y piedras, Valladolid, 1572.

13 S. BOLIN, State and Currency in the Roman Empire to 300 AD, Estocolmo, 1958.

14 O. SEECK, "Die Münzpolitik Diocletians und seiner Nachfolger", Zeitschrift für Numismatik, 17 (1890), pp. 36-89 y 113-66; F. HEICHELHEIM, Wirtschaftsgeschichte des Altertums vom Paläolithikum bis zur Völkerwanderung der Germanen, Slaven und Araber, Leiden, 1938, pp. 776 ss. La simple pero perniciosa idea de M. FINLEY, The Ancient Economy (Updated with a New Foreword by Ian Morris), Berkeley, 1999, p. 196, según el cual "money was essentially coined metal and nothing else", parece ser compartida por muchos historiadores.

15 L. von MISES, The Theory... , pp. 79-90, ya advirtió la paradoja del dinero: que es demandado no por lo que es en sí, sino por lo que puede comprar. Sobre las críticas a su teoría y su defensa contra las mismas, $c f$. J.T. SALERNO, "Ludwig von Mises's Monetary Theory in Light of Modern Monetary Thought", The Review of Austrian Economics 8-1 (1994), pp. 71-115.

16 G. DEPEYROT, Crisis e inflación entre la Antigüedad y la Edad Media, Barcelona, 1996, pp. 134-6, atina, pero no lo explica. Entendida la problemática a través de la teoría monetaria austríaca, el asunto pasa a estar meridianamente claro. Como ejemplo de las limitaciones cuantitativistas, G. MICKWITZ, Geld und Wirtschaft im römischen 
Una subida de precios debido a una expansión de la oferta monetaria no es lo mismo que la expansión en sí, sino su primera y más obvia consecuencia. Resulta evidente -y más para un historiador- que una causa o condición no es lo mismo que una de sus consecuencias, siendo indispensable el discernir unas de otras. Emplear la palabra "inflación" en el sentido de "aumento de precios" conduce a una permanente confusión, al desviar la atención de las causas, algo intolerable para la adecuada comprensión y explicación de los fenómenos y procesos económicos. ${ }^{17}$

La inflación altera los precios y salarios, pero éstos jamás cambian por igual, al mismo tiempo y en directa proporción al volumen de moneda en circulación, como sostienen las tesis cuantitativistas. De hecho, trastoca toda la estructura productiva, y reduce en mayor medida el poder adquisitivo de aquellos con un menor nivel de ingresos, cuya única capacidad de ahorro se encuentra precisamente en la acumulación de dinero. Todo proceso inflacionario tiene, pues, ganadores y perdedores. Por ello creemos que no se puede entender la dinámica social de un período como el que nos ocupa sin considerar las alteraciones de la moneda.

Los economistas de la Escuela Austriaca, a pesar de su bagaje teórico, han caído en generalizaciones burdas y tesis decadentistas. Su aportación básica es el brevísimo ensayo de Ludwig von Mises Observations on the Causes of the Decline of Ancient Civilization, ${ }^{18}$ que data de 1949 y se basa casi en exclusiva en la obra de Mikhail Rostovzeff, ${ }^{19}$ a la vez muy influida por la revolución bolchevique.

\section{LA MONETIZACIÓN DE LA SOCIEDAD TARDOIMPERIAL}

No podemos abordar la evolución monetaria sin entender el grado en que tanto el ciudadano como el gobierno se hallaban expuestos a los perjuicios ocasionados por la alteración del dinero, es decir, la extensión de la economía monetaria romana.

Como bien señala Chris Wickham, tendemos a considerar demasiado a menudo el Imperio Romano como un todo uniforme, cuando en realidad se trataba más bien de una colección de economías regionales vinculadas entre sí. ${ }^{20}$ Con todo, al nivel del conjunto imperial, y contra la idea de depauperación general, el siglo IV fue en apariencia un período de prosperidad y restablecimiento tras el catastrófico siglo III. ${ }^{21}$

Reich des 4. Jahrhunderts, Helsinki, 1932, p. 47, rechazaba de forma expresa que la alteración de la ley devaluara la moneda si la oferta monetaria permanecía constante.

17 R.S. BAGNALL, Currency and Inflation in Fourth Century Egypt, Atlanta, 1985, constata que los incrementos de precios fueron resultado de las mutaciones monetarias, y no un fenómeno independiente.

18 L. von MISES, Human Action: a Treatise on Economics, San Francisco, 1966, pp. 767-9. Economistas posteriores han mantenido sus tesis sin profundizar, por ejemplo, J. HUERTA DE SOTO, Dinero, crédito bancario...., p. 50.

19 M. ROSTOVZEFF, Social and Economic History of the Roman Empire, Oxford, 1926.

20 C. WICKHAM, Framing the Early Middle Ages, Europe and the Mediterranean, 400-800, Oxford, 2005 , p. 3; toda la obra es un análisis esclarecedor de las distintas economías regionales.

21 Cf. J. BANAJI, Agrarian Change in Late Antiquity. Gold, Labour, and Aristocratic Dominance, Oxford, 2004, para el caso del siglo IV, aunque quizá peque de un exceso de optimismo. Para M. MCCORMICK, Orígenes de la economía europea. Viajeros y comerciantes en la Alta Edad Media, Barcelona, 2005, p. 46, la tendencia general entre los años 200 y 700 es decreciente, sin que ello implique un declive constante y universal, con lo cual coincidimos. A pesar de la valía de esta obra, nos da la impresión de que peca de decadentismo y subestima la economía tardoimperial en relación a la altomedieval. G. DEPEYROT, Crisis e inflación..., p. 8, considera los veredictos positivos sobre el siglo IV como el resultado de "las teorías reaganianas y thatcherianas del «menos Estado»”, y se contradice a sí 
Según la idea tradicional de Moses Finley -aún no superada, y repetida hasta la saciedad sin sentido crítico alguno-, ${ }^{22}$ la romana fue una economía natural cuyas ciudades eran meros parásitos producto de la burocracia imperial, en la que el comercio tenía poca entidad y la moneda -introducida por el Estado con carácter fiscal- escaseaba. ${ }^{23}$ En esta línea, Michael Crawford, desde presupuestos polanyistas, estimaba consumado el fin de la economía monetaria para el reinado de Teodosio I. ${ }^{24}$

Entre las teorías más optimistas, destacamos a Keith Hopkins, defensor de una elevada monetización, así como de la existencia de una amplia distribución interregional y una economía muy integrada, dentro de la idea de una moneda de origen fiscal y un Estado motor de los intercambios. Lo recaudado en la provincias productoras de impuestos (Hispania, Sur de la Galia, África del Norte, Grecia, Asia Menor, Siria y Egipto) sería de tal modo redistribuido en dos anillos formados por las áreas consumidoras (uno externo, las fronteras con sus ejércitos, y otro central, RomaItalia, la sede imperial) gracias al gasto estatal, en especial el militar. ${ }^{25}$ Por su parte, Christopher Howgego también aboga por una gran monetización, pero rechaza un modelo tan homogéneo y fiscalista, considerando el comercio como el verdadero impulsor de la moneda. ${ }^{26}$

Otorgando un papel fundamental a la iniciativa privada, Elio Lo Cascio ha constatado la existencia de un mercado libre durante todo el Imperio Tardío, a pesar de una mayor intervención estatal, ${ }^{27}$ que, en todo caso, no se puede equiparar en modo alguno con nuestra propia experiencia coetánea. En la misma línea, John Paterson critica a Hopkins y defiende la existencia de una economía de mercado muy desarrollada, ${ }^{28}$ extremo que Peter Temin considera demostrado en el caso del Principado, ${ }^{29}$ y que Andrej Zgur se encarga de probar in extenso. ${ }^{30}$ Un aspecto de capital

mismo - al igual que una multitud de historiadores- al considerar el "Bajo Imperio" un período de crisis y depauperación constante, a la vez que reconoce que se trató de una época durante la cual se recuperó de la catastrófica crisis del siglo III (G. DEPEYROT, Crisis e inflación..., pp. 11-4 y 160-2).

22 M.I. FINLEY, The Ancient Economy... El largo debate entre modernistas y primitivistas es reflejo del estéril cisma de la antropología económica entre formalistas y sustantivistas. Las tesis de Finley han sido refutadas por K. GREENE “Technical Innovation and Economic Progress in the Ancient World: M.I. Finley Re-Considered”, Economic History Review, 53:1 (2000), pp. 29-59.

23 M.I. FINLEY, The Ancient Economy..., p. 166. Como bien señala K.W. HARL, Coinage in the Roman Economy, 300 BC to AD 700, Baltimore, 1996, p. 3, las referencias para tan tajante afirmación datan únicamente de 66 a.C. a 33 d.C. período en el que se padecía la ausencia de cualquier emisión substancial de bronce, y en el que los aristócratas andaban escasos de efectivo en su ansia por apoderarse de las vastas cantidades de tierras disponibles a raíz de las guerras civiles y sucesivas purgas.

24 M. CRAWFORD, "Money and Exchange in the Roman World", Journal of Roman Studies (en adelante JRS) 60 (1970), pp. 40-8. Las ideas que desarrolla en este artículo las repite en obras más recientes.

25 K. HOPKINS, “Taxes and Trade in the Roman Empire (200 BC - 400 AD)", JRS, 70 (1980), pp. 101-25, muy criticado por R. DUNCAN-JONES, The Economy of the Roman Empire, Cambridge, 1982, que con todo reconoce la elevada monetización de las áreas urbanas.

26 C.J. HOWGEGO, "Why the Ancient States Strike Coins?", The Numismatic Chronicle, 150 (1990), pp. 1-25, y Ancient History from Coins, Londres, 1995.

27 E. LO CASCIO, "Mercato libero e «commercio amministrato» in età tardoantica", en ZACCAGNINI (ed.), 2003, pp. 307-325, y “The role of State in the Roman economy”, en P.F. BANG, M. IKEGUCHI y H.G. ZICHE (eds.) Ancient Economies, Modern Methologies, Bari, 2007.

28 J. PATERSON, "Trade and Traders in the Roman World: Scale, Structure and Organization", en H. PARKINS y C.H. SMITH (eds.), Trade, Traders and the Ancient City, Londres, 1998, pp. 149-167.

29 P. TEMIN, "The Economy of the Early Roman Empire", Journal of Economic Perspectives, 20 (2006), pp. 133-51, aunque el autor peque de decadentismo al referirse al Imperio Tardío.

30 A. ZGUR, The Economy of the Roman Empire in the First Two Centuries A.D., An Examination of Market 
importancia a este respecto es que los códigos Teodosiano y Justinianeo definían el precio justo (iustum pretium) como aquel al que llegan de forma libre y voluntaria un comprador y un vendedor adultos en ausencia de fraude - es decir, el precio del libre mercado-, con una importante reserva: en caso de acaparamiento o emergencia las autoridades imperiales se reservaban el derecho a intervenir (pensemos en el Edicto de Diocleciano). ${ }^{31}$

Creemos que estos estudios derriban por completo las viejas teorías primitivistas y estatalistas sobre la economía romana, así como la idea de un Dominado caracterizado por los controles o la manipulación de precios y el avance totalitario del Estado. ${ }^{32} \mathrm{Si}$ los unimos a la simple evidencia de las propias monedas -emitidas en cantidades gigantescas- parece demostrado que, en general, la economía tardorromana estaba muy monetizada, ${ }^{33}$ que la oferta monetaria era más que suficiente, ${ }^{34}$ y que los intercambios comerciales tenían gran importancia, ${ }^{35}$ sin que ello signifique menospreciar el papel capital del sistema fiscal.

Capitalism in the Roman Economy, Aarhus, 2007.

31 Cf. J.W. BALDWIN, "The Medieval Theories of the Just Price: Romanists, Canonists, and Theologians in the Twelfth and Thirteenth Centuries", Transactions of the American Philosophical Society, 49-4 (1959), pp.1-92, y K.S. CAHN "The Roman and Frankish Roots of Just Price of Medieval Canon Law", Studies in Medieval and Renaissance History, 6 (1969), pp. 1-52. G. DEPEYROT, Crisis e inflación ..., pp. 136-43, indica que las tasaciones de precios fueron esporádicas y contraproducentes.

32 Cf. P. HEATHER, "New Men for New Constantines? Creating an Imperial Elite in the Eastern Mediterranean", en P. MAGDALINO (ed.), New Constantines: The Rhythm of Imperial Renewal in Byzantium, 4th-13th Centuries, Londres, 1994, pp. 11-33, donde viene a demostrar que la aplastante burocracia tardoimperial era en realidad bastante limitada y su expansión no exigió grandes desembolsos adicionales. Véase también J.F. MATTHEWS, Western Aristocracies and the Imperial Court AD 364-425, Oxford, 1975, pp. 32-100, y C. KELLY, Ruling the Later Roman Empire, Londres, 2004.

33 Si para M. CRAWFORD, "Money and Exchange...", p. 45, el intercambio monetario estaba prácticamente limitado a las ciudades, C. HOWGEGO, "The Supply and Use of Money in the Roman World 200 BC to AD 300", $J R S, 82$ (1992), pp. 1-31, considera que la moneda se empleó extensamente en áreas rurales, un extremo avalado por F. MILLAR; “The World of the Golden Ass”, JRS, 71 (1981), pp. 63-75. G. DEPEYROT, “L'or et la société du Bas Empire (IVe-Ve siècles)", Numisma, 180-185 (1983), p. 94, manifiesta que la monetización de la sociedad romana es un hecho establecido en la historiografía tardoimperial. Para K.W. HARL, Coinage ..., pp. 4, 252 y 267-268, la moneda debió seguir los mismos ciclos estacionales campo-ciudad documentados en la Europa medieval: los agricultores la obtenían vendiendo sus productos en los mercados urbanos, y la gastaban en ferias rurales, préstamos, compra de tierras y pago de impuestos.

34 Cf. M.F. HENDY, Studies in the Byzantium Monetary Economy c. 300-1450, Cambridge, 1985, pp. 257-303 (aunque su visión sea la de una moneda fiscal), y J. BANAJ, Agrarian Change ..., pp. 39-88. G. DEPEYROT, Crisis e inflación..., pp. 214-19, insiste en una escasez estructural de oro.

35 A través de los estudios de R. HODGES y D. WHITEHORSE, Mohammed, Charlemagne and the Origins of Europe, Londres, 1983, se confirma la persistencia de la vida comercial, aunque a menor escala, hasta pleno siglo VI. Puede hallarse una moderna visión sintética de la economía tardoimperial -a nuestro juicio en exceso decadentista- en M. MCCORMICK, Orígenes..., pp. 41-125, que confirma la pervivencia de las redes comerciales de largo recorrido en lo más tenebroso de la "Edad Oscura". Uno de los más notorios investigadores del período defiende que la vida económica y el comercio eran dirigidos por la actividad fiscal del Estado, $c f$. C. WICKHAM, Framing..., pp. 535-41 y 693-824. Wickham, al aceptar la vieja falacia marxista del polilogismo de clases, en la idea de que cada "modo de producción" tiene su propio pensamiento económico autojustificativo, acata igualmente el polanyismo y su concepción sustantivista de la economía. Aunque el autor afirme que ello no condiciona su conclusión de que fue la involución del sistema fiscal romano y las aristocracias la que colapsó el comercio a larga distancia, está claro que lo hace, sin que ello vaya en demérito de su monumental obra. 


\section{EVOLUCIÓN DE LA MONEDA DURANTE EL SIGLO IV ${ }^{36}$}

\subsection{El sistema monetario de Diocleciano}

El declive y caída del denario, y su sustitución por el antoniniano es un proceso bien conocido, así como la devaluación de este último. ${ }^{37}$ Nadie discute seriamente el hecho de que fue la constante devaluación monetaria la que impulsó un espectacular incremento de los precios y un caos económico - aliado con los vaivenes políticos- que las nuevas monedas de Aureliano no lograron estabilizar del todo. ${ }^{38}$

Como parte de su programa reformista, a partir de 293 Diocleciano pretendió poner orden en la economía desmonetizando las piezas en circulación e implementando un nuevo sistema para todo el Imperio en un proceso que se extendió hasta 297-8..$^{39}$

Debido al vicio de la especialización y compartimentación del conocimiento, se tiende a separar la economía de todo lo demás, y no se ubica esta reforma monetaria en el contexto político contemporáneo. Durante los años 293 y 294 Diocleciano permaneció en el limes danubiano, nominalmente en Sirmio (Panonia), aunque sus desplazamientos fueron incesantes, desde Mesia hasta la Propóntide. ${ }^{40}$ Fue un período de relativa paz tras sus campañas a lo largo de la década precedente. ${ }^{41}$

Este emperador creó un nuevo sistema de cecas repartidas por todo el Imperio, que, tras diversos cambios, se estabilizarían en las quince ciudades que muestra la Fig. 1. ${ }^{42}$ Todas ellas eran grandes puertos marítimos y/o fluviales - desde los cuales era más sencillo distribuir la moneda- y se situaban estratégicamente cerca de las fronteras. ${ }^{43}$

Diocleciano se inspiró directamente en el sistema monetario egipcio, heredado de los Ptolomeos y mantenido durante el Principado. ${ }^{44} \mathrm{~A}$ pesar de que valor nominal de sus dracmas de bronce

36 Además de las citadas más adelante, las principales obras empleadas en este apartado son G. DEPEYROT, "Le système monetaire de Diocletien à la fin de l'Empire Romain", Revue Belgue de Numismatique, 138 (1992), pp. 33-106, y C. E. KING, “The Fourth Century Coinage”, en L. CAMILLI y S. SORDA (eds.), L”'inflazione” nel Quarto Secolo, Roma, 1993, pp. 1-87.

37 Cf. K.W. HARL, Coinage..., pp. 125-43; S. ESTIOT. "De Pertinax à la réforme de Dioclétien (192-294)", en M. AMANDRY y D. BATESON (ed.), A Survey of Numismatic Research 2002-2007, Glasgow, 2009, pp. 157-174.

38 K.W. HARL, Coinage..., p. 143-8; J. LAFAURIE, "Réformes monétaires d'Aurélien et de Dioclétien", Revue numismatique, 6-17, (1975), pp. 73-138.

39 K.W. HARL, Coinage..., p. 151.

40 T. BARNES, The New Empire of Diocletian and Constantine, Cambridge, 1982, p. 49 ss.

41 Contra sármatas (285 y 289), persas (287), germanos (288) y sarracenos (290), y las de Maximiano contra los bagaudas, germanos y Alecto en la Galia (285, 287 y 289), $c f$. T. BARNES, The New Empire..., pp. 52-3.

42 M. HENDY, "Mint and Fiscal Administration under Diocletian, His Colleagues and His Successors: A.D. 305- 324”, JRS, 62 (1972), pp. 75-82; Studies in the Byzantium..., pp. 378-94; R. DELMAIRE, Largesses sacrés et res privata. L'aerarium impérial et son administration du IVe au VIe siècle, Roma, 1989, pp. 495-517.

43 A excepción de Roma y las cecas temporales de Cartago, Ostia y Serdica. No resulta extraño que Hispania y África (tras el cierre del taller de Cartago) no tuvieran ceca propia. Ambas diócesis, en las que no existía una amenaza militar tan apremiante como en Oriente o en el limes septentrional, podían aprovisionarse adecuadamente con moneda procedente de la cuenca del Ródano (Arlés-Lyon), la propia Roma, o las cecas atlánticas de Londres y Tréveris, merced a la extensión de sus costas y la existencia de grandes vías fluviales que penetran en el interior, en el caso de Hispania.

44 G. DEPEYROT, Crisis e inflación..., pp. 206 ss; K.W. HARL, Coinage..., p. 151. Sobre su final, cf. G.M. STAFFIERI, "Testimonianze sulla fine della monetazione autónoma alessandrina (296-298 d.C.)", en C. ALFARO 


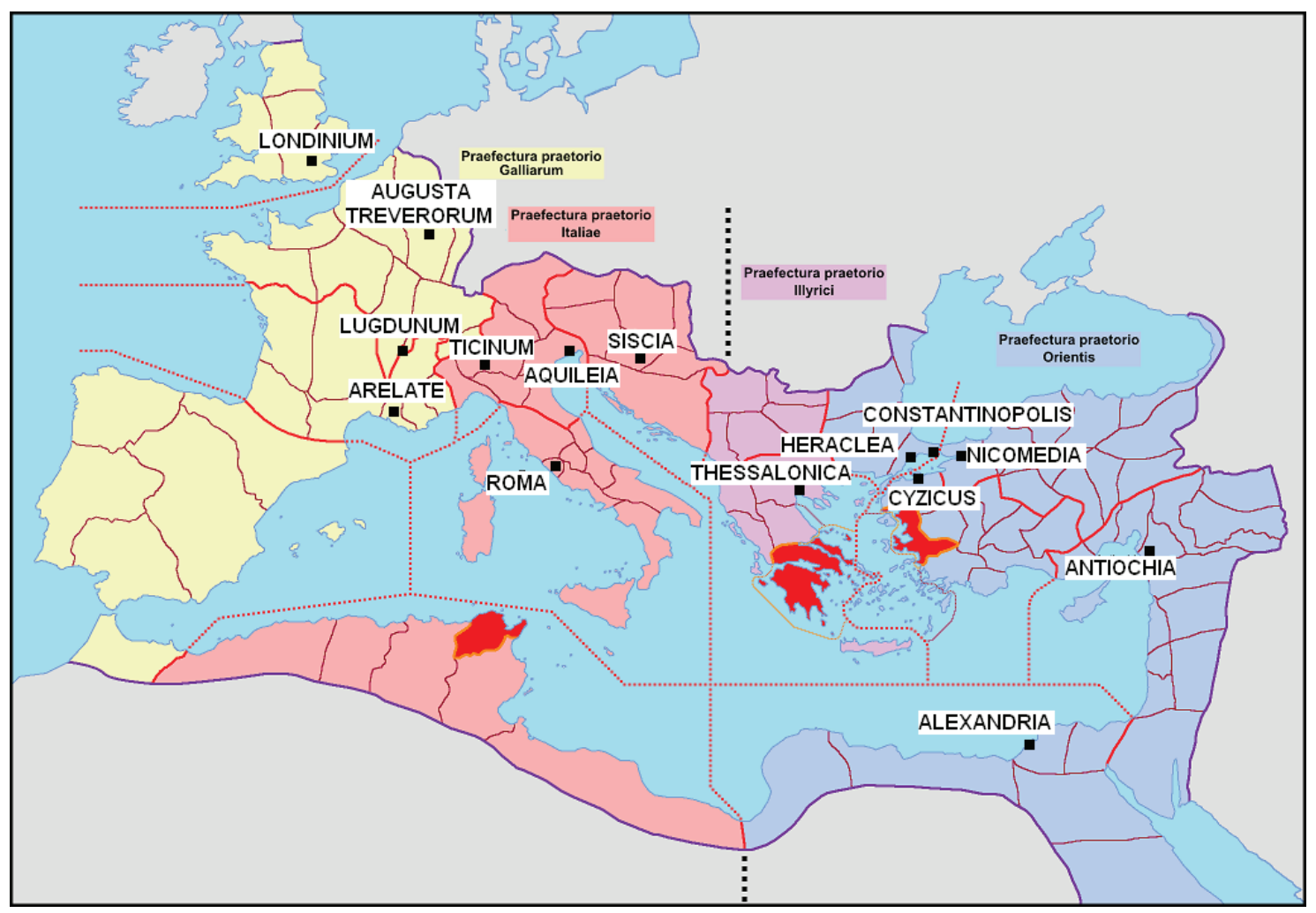

Fig. 1. Cecas romanas en el s. IV.

y tetradracmas de vellón excedía con mucho al intrínseco, tuvo éxito gracias al correcto ajuste entre denominaciones, la estabilidad de peso y ley, el control de las cantidades acuñadas, la ausencia de cualquier moneda buena que compitiera y su circulación restringida a Egipto. ${ }^{45}$

El nuevo sistema, basando en la tradición imperial romana, contaba con piezas de oro y plata, y calderilla de metal vil, en este caso vellón, cuyo valor intrínseco dependía de la plata que contenía. Sus principales elementos eran los siguientes: ${ }^{46}$

a) Una moneda de oro puro (99\%), muy probablemente llamada ya solidus, con una talla de 60 por libra y un peso habitual de unos 5'3 g. La diferencia con el peso teórico, es decir, el señoraje, sería de 0’15 g, un 2’75\%.

b) Una moneda de plata pura (96-7\%), el argénteo, con una talla de 96 por libra, y un peso aproximado de 3’3 g. El señoraje sería así de 0’11 g, el 3’25 \%.

c) Una moneda de vellón grande, el nummus, con una talla de 32 por libra, un peso de unos 10 ' $15 \mathrm{~g}$ y un contenido de plata en torno al $4 \%$.

ASINS, C. MARCOS ALONSO, P. OTERO MORÁN (coords.), XIII Congreso Internacional de Numismática, Madrid, 2003: actas, Madrid, 2005, vol. 1, pp. 937-946.

45 K.W. HARL, Coinage..., pp. 122-4.

46 Evitándonos complicaciones, seguimos a C.H.V. SUTHERLAND y R.A.G. CARSON (eds.), The Roman Imperial Coinage (en adelante RIC) vol. VI, Londres, 1967, pp. 93-100, y a K.W. HARL, Coinage..., pp. 148 ss. Había, naturalmente, elementos adicionales, múltiplos y submúltiplos, que no trataremos. 

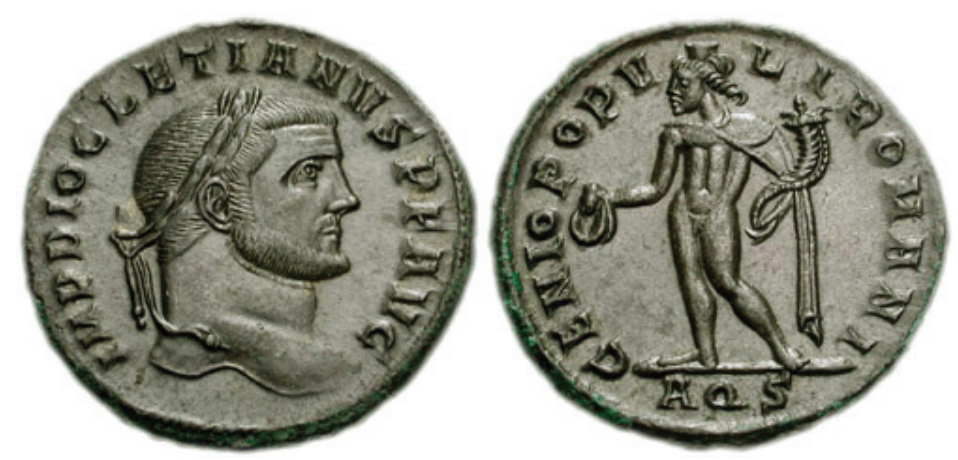

Fig. 2 Nummus aquilense de Diocleciano, tipo Genio Populi Romani.

d) Una moneda de vellón intermedia, el neoantoniniano (o radiado, por el tipo de corona), con una talla de 110 por libra, un peso de $3 \mathrm{~g}$ y un 0 ' $1 \%$ de plata. ${ }^{47}$

e) Una moneda de vellón pequeña, el denario (o laureado), con una talla de 220 por libra, un peso de unos 1'5 g y un (presunto) 0 '05\% de plata.

El poder adquisitivo de cada moneda estaba determinado por su valor en la unidad de cuenta, el llamado "denario común", equivalente al laureado. Mientras que tanto el oro como la plata se ajustaban a su valor intrínseco, las piezas de vellón estaban muy sobrevaloradas, lo que fue la perdición del sistema. Tal como explicaba el economista austríaco Friedrich von Hayek en unas reflexiones sobre la ley de Gresham, la moneda mala sólo expulsa a la buena si existe un precio mínimo para aquella y uno máximo para ésta. En cualquier otro caso la gente opta por la buena. ${ }^{48}$

Debido a ello, desde sus mismos inicios el vellón de Diocleciano estuvo condenado a no ser aceptado al cambio oficial, y a devaluarse en relación a las monedas buenas, que se atesoraron de forma masiva mientras el nummus copaba el mercado, empleándose en toda clase de transacciones, y no sólo en las menudas. ${ }^{49} \mathrm{Y}$ ante la disyuntiva de pagar con oro y plata puros, que conser-

47 K.W. HARL, Coinage..., p. 151

48 F. A. von HAYEK, Choice of Currency: a Way to Stop Inflation. Londres, 1976, pp. 18-9. La formulación correcta de la ley de Gresham es, por tanto, "la moneda mala expulsa a la buena si sus tipos de cambio están fijados por ley".

49 J.P. CALLU, La politique monétaire des Empereurs romains de 238 à 311, París, 1969, pp. 393-394, y G. DEPEYROT, Crisis e inflación..., p. 211, suponen que las nuevas monedas no se integraron en la masa de antoninianos circulantes y que su "elevado valor" con respecto a éstos provocó que salieran de la circulación, atesorádose. Si una importante cantidad de antoninianos de Galieno y Claudio II, así como piezas póstumas e imitaciones a nombre de este último (con una ley en torno al 2\%, frente al 4\% del nummus), siguió en circulación durante el primer cuarto de la siguiente centuria fue porque, aparte de los inmensos volúmenes existentes, tenían la ventaja de que sus tipos de cambio no estaban fijados por ley (vide nota 48). En todo caso, interpretar y pretender extraer conclusiones universales de un conjunto mayor o menor de tesoros particulares en los que incidieron una miríada de factores que nos son desconocidos sigue siendo una tarea compleja y, en ocasiones, impracticable, sin importar cuánto se "cocinen" las estadísticas. Véase, por ejemplo, R. BLAND, "The Changing Patterns of Hoards of Precious-Metal Coins in the Late Empire”, Antiquité tardive 5-5 (1997), pp. 29-55. Por añadidura, en la Tetrarquía, más segura que la era precedente, hay un descenso de los atesoramientos y un cambio de las motivaciones que condujeron al depósito de monedas, y por tanto de la representatividad muestral. Por último, cabe añadir que, a nuestro juicio, los hechos históricos sólo pueden entenderse a través de un cuerpo teórico previo bien asentado. Los datos por sí solos no prueban nada. 
vaban o incrementaban su valor, la elección era obvia. ${ }^{50} \mathrm{Ni}$ el carácter sagrado de la moneda,${ }^{51} \mathrm{ni}$ las draconianas medidas represivas lograron salvar la situación.

Así, por chocante que pueda resultar, el resultado fue una carestía estructural de dinero: al dominar la moneda mala todos los intercambios, la gente común no tenía suficiente como para realizar las transacciones diarias, haciendo necesaria la emisión de cantidades incluso mayores, carencia que se alió con la codicia fiscal del Estado. ${ }^{52}$

La base de la Teoría Austríaca del Ciclo Económico es que las mutaciones monetarias jamás son neutrales. ${ }^{53}$ Además de la menor calidad y mayor cantidad de monedas de vellón en circulación, es preciso considerar que entraron en la economía desde lugares concretos (las ciudades con ceca) y siempre a través de grupos sociales muy determinados, en especial el ejército y la burocracia imperiales. Lógicamente, se gastaron primero en bienes de consumo y servicios, y sólo después, poco a poco, fueron afectando al resto de la estructura productiva. Esto implica que los precios de los productos básicos de consumo variaron antes que los demás, comenzando por los grandes centros urbanos y las provincias con mayores concentraciones militares. Para averiguar cuáles fueron sólo es preciso observar los primeros artículos enumerados en el célebre Edictum de Pretiis Rerum Venalium, es decir, aquellos cuyo control era prioritario: grano, vino, aceite, carne, pescado, frutas y verduras, salarios y ropa.$^{54}$ Los beneficios de las industrias más próximas a los productos de consumo, como la cerámica, también comenzaron a elevarse. ${ }^{55}$ A nuestro juicio, de estos hechos se derivan en parte los problemas de las reconstrucciones de precios realizadas a partir de los papiros egipcios, y la imposibilidad de comprenderlas desde tesis cuantitativistas. ${ }^{56}$

50 Aunque, por extraño que pueda parecer, J.P. CALLU, La politique monétaire..., p. 428, sostiene que la circulación del oro fue "densa, estable y bien organizada", idea que J. BANAJI, Agrarian Change..., pp. 49-50, trata de apuntalar aludiendo a la existencia puntual de considerables tesoros de oro (aunque ello apunta más bien, precisamente, a que no circulaba). La insistencia en el pago de impuestos en metales preciosos y las compras obligatorias de los mismos por parte del Estado (coemptio auri argentique), pagadas, claro está, en vellón, son bien indicativas a tal respecto, $c f$. R. DELMAIRE, Largesses sacrés ..., pp. 347-50; J.-M. CARRIÉ “Observations sur la fiscalité du IV siècle pour servir a l'histoire monetaire”, en L. CAMILLI y S. SORDA (eds.), L”’inflazione”..., pp. 126-130.

51 Podemos apreciarlo en los reversos con figura estante de la diosa Juno Moneta sosteniendo una balanza y una cornucopia, acompañada por la leyenda SACRA MONET AVGG ET CAESS NOSTR, es decir, "la sagrada moneda de nuestros augustos y césares” (RIC VI, lám. 5, nº 40a). De tal modo, atentar contra la moneda constituía no sólo un crimen de lesa majestad, sino un sacrilegio.

52 K.W. HARL Coinage..., p. 155, cree que la emisión de cantidades excesivas de moneda se debió a la imposibilidad del gobierno de reemplazar con eficacia todo el numerario del Imperio, lo cual puede en parte ser cierto, pero cae en prejuicios cuantitativistas al juzgarla como la única causa de la inflación.

53 Cf. J. HUERTA DE SOTO, "La teoría austríaca del ciclo económico", en Cuadernos de economía 8-22 (1980), pp. 257-272; J. HUERTA DE SOTO, Dinero, crédito bancario...., pp. 135-396.

54 Secciones 1-10 de las 32 de que consta el Edicto, $c f$. S. CORCORAN, The Empire of the Tetrarchs, Imperial Pronouncements and Government AD 284-324, Oxford, 2000, pp. 205-33, y E.R. GRASER, "A text and translation of the Edict of Diocletian”, en T. FRANK, An Economic Survey of Ancient Rome, Baltimore, 1940, vol. 5, pp. $307-421$.

55 No es de extrañar, pues, la manifiesta prosperidad de las provincias de Oriente, Egipto y África, muy productivas y con facilidades para exportar al resto del Imperio por vía marítima. Durante toda la Antigüedad Tardía es notabilísimo el esplendor del comercio del Levante mediterráneo, en especial el sirio, $c f$. H. PIRENNE, Mahoma y Carlomagno, Madrid, 1981, pp. 66-79.

56 Cf. R.S. BAGNALL y P.J. SIJESTEIJN, "Currency in the Fourth Century and the Date of CPR V. 26”, Zeitschrift für Papyrologie und Epigraphik, 24 (1977), pp. 111-24; R.S. BAGNALL, Currency and Inflation ..., y "Fourth-Century Prices: New Evidence and Further Thoughts", Zeitschrift für Papyrologie und Epigraphik, 76 (1989), pp. 69-76; J.E. LENDON, "The Face on the Coins and Inflation in Roman Egypt”, Klio, 72, (1990), pp. 107-34. 
En teoría el gobierno imperial podría haber ido ajustando los valores legales de cada moneda según el mercado, pero en la práctica esta tarea es demasiado compleja, $\mathrm{y}$, en el fondo, iba contra el interés que le llevaba a emitir ingentes cantidades de moneda mala. Diocleciano se vio obligado a realizar una revaluación en 300, y al año siguiente intentó acabar con la escalada de precios que él mismo había provocado mediante el expeditivo método de ilegalizarla. Su Edicto de Precios establecía un precio y un salario máximo legal para virtualmente todos los productos y ocupaciones. La seriedad con que el Augusto consideró el problema puede apreciarse en el hecho de que prescribiera la pena de muerte para todo el que violara sus disposiciones. También se condenó a muerte a cualquiera que simplemente distrajera bienes del mercado para evitar estas medidas, una actuación obvia si no podía obtenerse un buen precio. Sin embargo, es evidente que de nada iba a servir tal severidad cuando era la propia política monetaria imperial la que causaba el problema. Lactancio registró exactamente lo que pasó: a pesar de la represión, hubo una retirada masiva de bienes y un aumento de precios incluso mayor, que condujo a la rescisión final del edicto. ${ }^{57}$

Pocos meses después de su entrada en vigor, en noviembre de 301, y tras el estrepitoso fracaso del control de precios, el Emperador tuvo que realizar un segundo ajuste de los valores nominales, con toda probabilidad tan fallido como los anteriores: ${ }^{58}$

\begin{tabular}{|llll|}
\hline & $\mathbf{2 9 3}$ & $\mathbf{3 0 0}$ & $\mathbf{3 0 1}$ \\
\hline Áureo & 1 & 1 & 1 \\
\hline Argénteo & 24 & 24 & 24 \\
\hline Nummus & 120 & 96 & 96 \\
\hline Radiado & 300 & 480 & 480 \\
\hline Laureado & 600 & 1.200 & 2.400 \\
\hline
\end{tabular}

Podemos apreciar que el valor nominal de cada pieza de vellón era muy superior al intrínseco. Según los valores establecidos en 293, al pagar 25 denarios comunes con un argénteo se entregarían 3'3 gramos de plata, mientras que si hacía con 5 nummus no se darían más que 2'05, e incluso menos en el caso de pagar con radiados y laureados. Ya que el valor intrínseco del cobre era ínfimo, la equivalencia entre argénteo y nummus hubiera debido ser de 1:8, y no 1:5 (293) ó $1: 4(300-1) .{ }^{59}$

A pesar de que los radiados y laureados eran todavía más inflacionistas, debieron escasear, puesto que hoy día su hallazgo es todo un acontecimiento. ${ }^{60}$ Quizá sea una apariencia debida en parte a la inutilidad de atesorarlas -al carecer de valor- o a las posteriores reacuñaciones del vellón, pero es lógico pensar que no fueron producidas en cantidad, ya que, al tratarse de piezas muy pequeñas, su acuñación resultaba cara en comparación con la emisión masiva del nummus, amén de sufrir un mayor desgaste y deterioro. Salta a la vista que los edictos monetarios pretendieron defender a éste último, aumentando incluso su valor nominal, mientras aceptaban el hundimiento

57 Lactancio, De mort. pers. 7, 6-7.

58 K.W. HARL, Coinage..., p. 151.

$59 \mathrm{Si}$, como afirmaban Callu y Depeyrot (vide nota 49), el nummus era atesorado por su elevado valor en comparación con los antoninianos, su revaluación al alza en 300/301 hubiera sido una completa locura.

60 R. REECE, “Coins and the Late Roman Economy”, en L. LAVAN (ed.), Theory and Practice in Late Antique Archaeology, Leiden, 2003, p. 121. 
de los radiados y los laureados. Si en efecto fue así, la escasez de piezas de menor debió hacer necesario emplearlo en los intercambios menudos, con el consiguiente aumento de precios y el redondeo al alza.

En mor de la brevedad, y debido a nuestra visión crítica de los enfoques cuantitativistas, en este trabajo hemos intentado soslayar la cuestión de cuánto subieron exactamente los precios, toda vez que hemos establecido que fue la consecuencia necesaria de la política monetaria imperial y que nunca guardan una proporción determinada entre sí. Las más modernas investigaciones sugieren que, a pesar de las devaluaciones de los primeros años del siglo III, la gran inflación comenzó realmente tras la muerte de Alejandro Severo en 235 y fue más aguda de lo que se suponía, en torno a una media del 8'6-8' 8\% anual, llegando a su culmen con Diocleciano y su malhadado Edicto de Precios, al exceder el $100 \%$ en el último trimestre de $301 .{ }^{61}$

Aunque no redujera el peso o la ley del nummus durante todo su reinado, la simple evidencia de sus sucesivos edictos indica que el nuevo sistema estuvo lejos de ser estable y no supuso en absoluto, como se ha afirmado tantas veces, la superación del problema monetario del siglo III. ${ }^{62}$

Contra la idea de un Diocleciano justiciero social, ${ }^{63}$ es preciso remarcar que, por buenas o malas que fueran sus intenciones, este emperador también intentó resolver sus necesidades financieras por vía monetaria. Su reforma coincidió con el nombramiento de los césares Galerio en Oriente y Constancio Cloro en Occidente ${ }^{64}$-a cada uno de los cuales se asignó su propio (y carísimo) ejército comitatense- ${ }^{65}$ y un nuevo ciclo de intensa actividad bélica. ${ }^{66}$ Es evidente que esas carísimas campañas, así como sus ambiciosos programas constructivos, ${ }^{67} \mathrm{se}$ financiaron con los fondos obtenidos de gracias a la reacuñación masiva del circulante y la emisión de vellón sobrevaluado. En este sentido, su política no fue tan revolucionaria como se ha pretendido, sino continuista con respecto a la de sus predecesores de la Anarquía Militar, y mal ejemplo para sus sucesores, al institucionalizar la inflación como parte del sistema monetario y los ingresos del Estado.

${ }^{61} C f$. P.-I. K. PRODOMÍDIS, "Another View on an Old Inflation: Environment and Policies in the Roman Empire up to Diocletian's Price Edict”, Centre of Planning and Economic Research Discussion Papers, 85, Atenas, 2006. A. WASSINK, "Inflation and Financial Policy Under the Roman Empire to the Price Edict of 301 AD", Historia, 40-4 (1991), pp. 465-93, estima la subida de precios del período 250-93 en un 3'65\% anual, y la de 293-301 en un 22 '28\%.

62 Como bien señala F. de MARTINO, Historia económica de Roma antigua, Madrid, 1985, pp. 485 ss.

63 Por ejemplo, J.P. CALLU, La politique monétaire..., p. 405 ss, sostenía que Diocleciano pretendía restablecer la moneda buena y la "verdad económica de los precios", combatiendo la especulación -juzgada como única causa del aumento de los mismos.

641 de marzo y/o 21 de mayo de 293. T. BARNES, The New Empire..., pp. 4 y 38, considera simultáneos los nombramientos, pronunciándose contra la fecha del 21 de mayo.

65 Lactancio, De mortibus persecutorum (en adelante, De mort. pers.) 7, 2.

66 Primero Constancio Cloro emprendió nuevas campañas contra el usurpador britano Carausio (286-93) -con el que se había pactado la paz en 289 tras el fracaso de Maximiano Hercúleo- y contra su asesino y sucesor, Alecto (293-6). De igual modo, tras casi cuatro años en el área danubiana, a finales de 294 Diocleciano partió para Oriente, donde se reanudaron las hostilidades con los persas. Mientras Maximiano combatía en Hispania y el Norte de África, Diocleciano se trasladó de nuevo al Danubio en 296-7 para contener a los carpos, campaña completada por Galerio en 299. En 297-8 él ambos se enfrentaron con éxito a la rebelión de Egipto y a la invasión sasánida, a resultas de la cual obtuvo la victoria más decisiva sobre los persas en muchos años, asegurando la hegemonía romana sobre Armenia y anexionándose el territorio entre el Tigris y el Gran Zab. Para acabar, entre 300 y 304 Constancio mantuvo a raya a francos y alamanes en el Rin.

67 Como las residencias imperiales de Sirmio, Nicomedia, Split, etc, o sus construcciones y restauraciones en Roma (foro de César, Curia Julia, termas Dioclecianas, etc). Lactancio (De mort. pers. 7, 8-10) le atribuía una cupiditas aedificandi. 


\subsection{La evolución del vellón en el siglo IV ${ }^{68}$}

La moneda de vellón, emitida en cantidades gigantescas, es el numerario dominante a lo largo del siglo IV, y su estudio una tarea ardua y compleja, por lo general evitada. ${ }^{69}$ Para empezar, ni siquiera tenemos claro su propio nombre. Hubo autores que denominaron a estas monedas "pequeños bronces", de forma harto ambigua, inexacta y equívoca. Tras largos debates, se la llamó "follis", y últimamente se ha impuesto la forma más correcta "nummus". Pero estas dudas con respecto a la denominación no son nada en comparación con los desafíos metrológicos que presenta. Debido a ello los numismáticos han clasificado las monedas de acuerdo a su diámetro, estableciendo cuatro categorías: AE1 (32-26 mm), AE2 (25-21 mm), AE3 (20-17) y AE4 (menos de $17 \mathrm{~mm}$ ). Por si fuera poco, desconocemos en gran medida los cambiantes valores nominales, otro de los grandes factores del desbarajuste monetario del siglo IV. Debido a la escasez de fuentes es probable que jamás lleguemos a conocerlas, pero es lógico pensar que el erario devaluaría o supervaloraría el vellón según le conviniera. ${ }^{70}$ El gráfico muestra de la forma más simplificada posible la evolución del peso y el contenido de plata del principal circulante de vellón ${ }^{71}$ a lo largo del siglo ${ }^{72}$.

Como puede observarse, durante el reinado de Constantino (307-37) la devaluación fue casi constante, con unas espectaculares reducciones de ley y peso entre los años 307 y 313 , que convirtieron al nummus en una pieza de 4'5 g (1/72) con una ley del 1'5\%. A continuación hubo un período algo más estable hasta 330, en que los cambios de ley se compensaron con variaciones del peso y viceversa, con toda probabilidad para intentar que las mutaciones pasaran desapercibidas mayor tiempo.

Las nuevas monedas de 330-48 comenzaron con una talla de 132 por libra (2'48 g) y una ley del 1\%. Su talla se redujo a $1 \frac{1}{196}$ en 336, y bajo los hijos de Constantino (337-61) continuó la devaluación, menos y menos lucrativa cada ocasión, lo que condujo a la emisión de volúmenes mayores y probablemente a cambios nominales. ${ }^{73}$

68 C.H.V. SUTHERLAND y R.A.G. CARSON (eds.), RIC VI, pp- 94-105; RIC VII, Londres, 1966, pp. 8-13; RIC VIII, Londres, 1981, pp. 59-67; RIC IX, Londres, 1951, pp. xxxix-xxxiii; Ma del M. ROYO MARTÍNEZ y J.J. MORENO CASANOVA, Las monedas de bronce del Bajo Imperio (346-408), Madrid, 2008. Sobre las características técnicas de la aleación de vellón, $c f$. C. VLACHOU, J.G. MCDONELL y R.C. JANAWAY, "Experimental Investigation of Silvering in Late Roman coinage", Materials Research Society Symposia Proceedings, 712 (2002), pp. $461-470$.

69 Sirva de ejemplo G. DEPEYROT, Crisis e inflación..., p. 127, que considera "muy difícil juzgar el efecto o la relación entre las reformas de la amonedación y el aumento de los precios" y, fiel a este criterio, se abstiene por completo de hacerlo, centrándose en el sólido, despreciando por completo el vellón, ignorando su envilecimiento e insistiendo en la escasez crónica de numerario.

70 Sabemos de cambios nominales bajo Diocleciano - ya mencionados-y bajo Licinio, cuyo nummus fue reevaluado de 25 a 12'5 denarios comunes tras reducir su peso y ley, $c f$. K.W. HARL, Coinage ..., p. 165.

71 AE1 hasta 307, AE2 de 307 a 313, AE3 de 313 a 348, AE2 del 48 al 52, AE3 del 52 al 61; AE1 del 62 al 67 ; AE3 del 69 al 79; AE2 del 79 al 88, AE4 del 88 al 95. Buscando la comprensión y la máxima simplicidad, omitimos las diversas fracciones que hubo en cada momento y las metrologías paralelas producidas por la turbamulta de emperadores rivales y usurpadores a lo largo del período.

72 Según el RIC, vide nota 68.

73 Las monedas del tipo Gloria Exercitus (fig. 3) se emitieron en cantidades gigantescas entre los años 330 y 348 y en apariencia esta reacuñación logró reemplazar al numerario precedente. Contamos con tres grandes tesoros hasta cierto punto representativos de la circulación de esta época, todos británicos: el de Thornbury (2004), que constaba de 11 radiados y 11.449 nummi, 11.232 de los cuales eran del tipo Gloria Exercitus; el de Bishop's Wood (1895), 


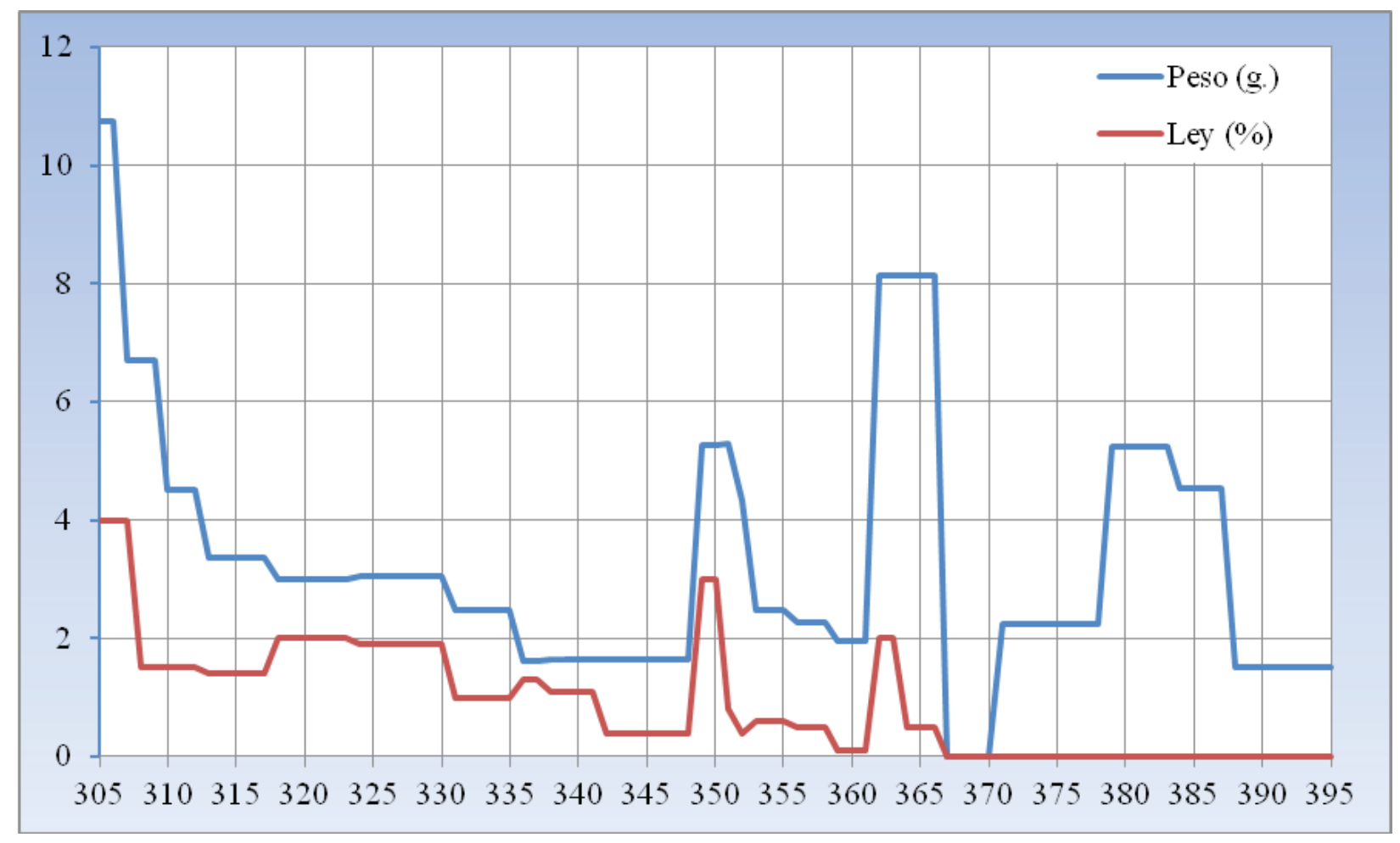

La primera y más obvia consecuencia del caos monetario fue una espectacular subida de los precios. No podemos seguir con detalle el curso de su escalada a lo largo del período, pero George Depeyrot calcula una impresionante media anual del $17 \%$ entre 305 y $368 .{ }^{74}$

Las frecuentes reformas monetarias sembraron asimismo la confusión, en especial con las deudas, provocando la proliferación de conflictos por las mismas. ${ }^{75}$ Entonces como ahora, quien estuviera endeudado se beneficiaba de la rápida depreciación del capital prestado. Los prestamistas, por supuesto, debieron implementar dispositivos anti-inflación en sus acuerdos, como por ejemplo garantizarlos en oro, de modo que el reembolso en vellón se ajustara a su valor en dorado metal al momento de la entrega. ${ }^{76}$ Además, la resistencia a aceptar moneda mala ralentizó

con 17.548 piezas, 8.722 de este tipo; y, finalmente, el de Nether Compton (1989), que contaba con 22.670 monedas no catalogadas, pero una muestra indicó que más del 90\% también eran Gloria Exercitus. Cf. M.E. BAGNALLOAKELEY, “A hoard of Roman coins found at Bishop's Wood in 1895”, The Numismatic Chronicle, Londres, 1896, pp. 209-37; F. HITCHCOCK (ed.) Treasure Annual Report 2004, Londres, 2005, pp. 181-2. E. LO CASCIO, “Aspetti della política monetaria nel IV secolo", en Atti dell'Academia Romanistica Costantiniana. X convegno Internazionale in onore di Arnaldo Biscardi, Nápoles, 1995, pp. 496-8, estima que es con este nuevo tipo, en 330, cuando se abandona el cambio fijo entre el nummus y el sólido.

74 G. DEPEYROT, Crisis e inflación..., pp. 130-2. R.S. BAGNALL, Currency and Inflation..., p. 64, estima el alza de los precios del trigo egipcio para el período 305-80 en el 14'4\%. Sobre las pantanosas discusiones acerca de los precios, $c f$. L. CAMILLI y S. SORDA (eds.), L'”inflazione”..., pp. 195-216.

75 Cf. G. DEPEYROT, Crisis e inflación..., pp. 147-50 y 292-3, aunque el autor no relaciona los problemas de deuda con las alteraciones monetarias, sino que parece atribuirlos a una especie de vicio consubstancial al préstamo de dinero. Nadie presta ni pide prestado dinero si va a salir perjudicado. Otra cosa bien distinta es que un posterior arbitrio monetario convirtiera lo provechoso en lesivo.

76 Se nos ocurre que tal método se extendiera a otros intercambios, y quizá sea así como debamos entender la afirmación del anónimo DRB II, 1, según la cual el oro sustituyó al cobre incluso en las transacciones menudas: se seguiría pagando en moneda física de cobre, pero según su valor en oro. Con todo, esta obra es un arbitrio tendencioso 

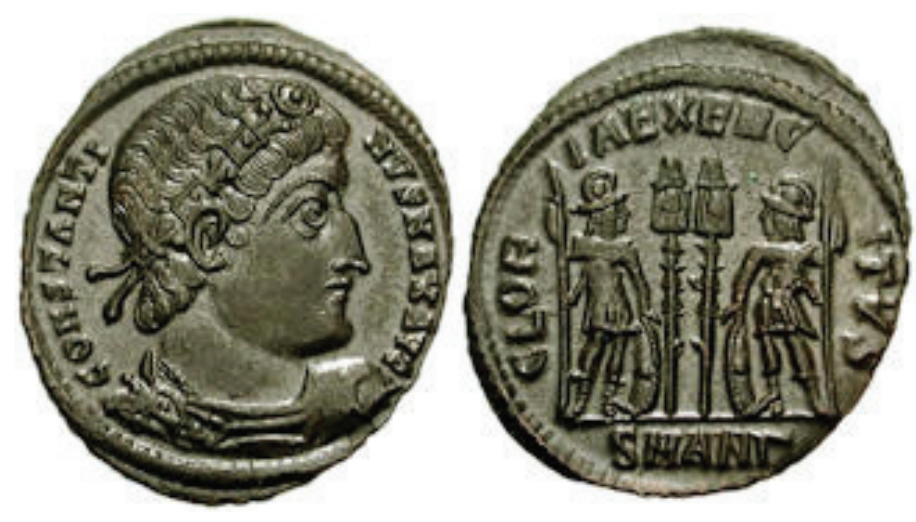

Fig. 3 Nummus antioqueno de Constantino el Grande, tipo Gloria Exercitus.

necesariamente los intercambios. Por añadidura, cada nueva alteración debió significar la parálisis de las actividades mercantiles, crediticias y cambiarias, ya que nadie desearía correr el riesgo de tener vellón en su poder al producirse la devaluación, lo que necesariamente hubo de encarecer las operaciones que realmente se hicieron y provocar desabastecimientos. ${ }^{77}$

Puesto que la mayor parte de la población tanto agrícola como urbana no era capaz de producir lo suficiente como para poder acceder al oro o la plata, estaba a merced de la inflación del vellón y sus perniciosos efectos. ${ }^{78}$ En cambio, los potentiores no sólo estaban a salvo de la misma, sino en situación de beneficiarse enormemente, ${ }^{79}$ lo que resultó en la acumulación de patrimonios

con claros prejuicios anticonstantinianos.

77 El abastecimiento de los centros urbanos era uno de los grandes quebraderos de cabeza de las sociedades preindustriales. Factores exógenos como las oscilaciones climáticas o las mutaciones monetarias rompían constantemente el frágil equilibrio entre oferta y demanda, de modo que en cualquier tiempo y lugar podían producirse situaciones de escasez. Mientras que los mayores centros urbanos dependían de la annona imperial, en el resto se implementaron sistemas de depósito municipales (lo que en España se llamaron pósitos y alhóndigas) que, bajo diversas formas, pervivieron hasta la Edad Contemporánea. A tal respecto, cf. P. GARNSEY, Famine and Food Supply in the Graeco-Roman World: Responses to Risk and Crisis, Cambridge, 1989 y J. DURLIAT, De la ville antique á la ville Byzantine. Le probléme des subsistances, Roma, 1990. Así por ejemplo, los problemas que atravesaba Antioquía del Orontes, a los que hubo de hacer frente el césar Constancio Galo (351-4), se aproximan de forma sospechosa a la gran devaluación emprendida en 352, cf. J.R. AJA SÁNCHEZ, "La crisis de Antioquía del año 354: un ejemplo de la pervivencia de la "Vis Publica" en la Antigüedad Tardía", Antigüedad y Cristianismo, 14 (1997), pp. 61-82, y Tumultus et urbanae seditiones: sus causas: un estudio sobre los conflictos económicos, religiosos y sociales en las ciudades tardorromanas (s. IV), Santander, 1998, pp. 39-72, con un carácter más general. La situación de hambre y disturbios se repetiría durante la estancia en Antioquía del hermano de Galo, Juliano, en 362, coincidiendo, no por casualidad, con la crisis monetaria del final del reinado de Constancio II y su propia reforma (vide nota 102), cf. $\mathrm{R}$. BROWNING, The Emperor Julian, Londres, 1975, pp. 149-75. Las hambrunas antioquenas documentadas en 313-4, 333, 354, 362, 375, 382, 384, 388-9 y 392 han sido estudiadas por J. DURLIAT. De la ville Antique..., pp. 350-81, aunque no advierte la correlación existente entre las mismas y las alteraciones de la moneda.

78 Incluso los soldados, remunerados preferentemente en metal precioso. Tenemos el caso de un centurión que murió a comienzos del siglo IV, y cuyo dinero fue inventariado (P.Oxy. XLVI 3307), por lo que pudo calcularse que, aproximadamente, el $80 \%$ era vellón y sólo el $20 \%$ oro, $c f$. A.K. BOWMAN, "The Economy of Egypt in the Earlier Fourth Century", en C.E. KING (ed.), Imperial Revenue, Expenditure and Monetary Policy in the Fourth Century A.D, Londres, 1980, p. 30 .

79 De rebus bellicis (en adelante DRB) II, 4. En este sentido, S. MAZZARINO, Aspetti sociali..., p. 114. tenía toda la razón cuando afirmaba que "I possessori d'oro si trovarono, d'un tratto, gli effettivi signori della società 
descomunales ${ }^{80}$ y el bien conocido fenómeno de la polarización social, a medida que los pequeños propietarios rurales y urbanos caían en la órbita de los poderosos para poder hacer frente a sus obligaciones fiscales. ${ }^{81}$ Por añadidura, aquellos personajes informados de la inminencia de una devaluación debieron estar en situación de lucrarse con facilidad.

A ello se unió el decaimiento de las rentas fijas. Como puede apreciarse en el Edicto de Diocleciano, los precios oficiales se tasaban en la moneda de cuenta, el denario común, aun cuando los pagos efectivos se realizaran en moneda de metal precioso. No es de extrañar entonces el hundimiento de aquellos curiales que no supieron o pudieron adaptarse a la situación, imitando a los más poderosos y sacando provecho de ella al hacerse responsables del cobro de tasas e impuestos. ${ }^{82}$

Al atesorarse la moneda buena (oro y plata), el Estado tomó medidas para blindarse ante su propia moneda inflacionaria, exigiendo que los contribuyentes realizaran sus pagos en moneda buena, exigiendo el pago de impuestos ${ }^{83} \mathrm{y}$ conmutando las entregas annonarias por pagos en metal precioso (aederationes). ${ }^{84}$ De tal modo, los impuestos que arruinaban a los romanos se convirtieron en el nexo de unión de la circulación paralela de moneda buena entre las capas sociales altas y vellón entre las bajas. Y de ahí la inmensa ventaja de los potentes sobre aquellos que estaban a merced del vellón, y la extensión del patronazgo y el colonato.

del quarto secolo", aunque lo hiciera por motivos equivocados. Sobre $D R B, c f$. D.N. SÁNCHEZ VENDRAMINI, "Consideraciones sobre el autor del De Rebus Bellicis y su valoración en la historiografía contemporánea", Temas Medievales, 17 (2009), pp. 139-63.

80 J.M. BLÁZQUEZ, "La crisis del Bajo Imperio en Occidente en la obra de Salviano de Marsella. Problemas económicos y sociales", Gerión, 3 (1985), pp. 157-82, recoge los escasos testimonios concretos sobre la extraordinaria riqueza del orden senatorial. Es famoso el caso de Santa Melania la Joven, que disfrutaba de posesiones dispersas por todo Occidente (Britania, Aquitania, Tarraconense, Sicilia, Campania, África Proconsular, Numidia, Mauritania y Roma), y unos ingresos que alcanzaban la astronómica cifra de 120.000 sólidos anuales, siendo los de su esposo Piniano otro tanto (Geroncio, Vita Melania, 11). Olimpiodoro (frag. 7) indicaba que, en época de Honorio, las primeras familias senatoriales de Roma tenían unas rentas anuales de 288.000 sólidos en efectivo y el equivalente a otros 96.000 en especie, un total de 384.000, cifra que, de ser cierta, casi quintuplicaría, por ejemplo, la recaudación imperial de la provincia de Numidia y nonuplicaría ampliamente la de la Mauritania Sitifensis (78.200 y 41.000 solidi, respectivamente; ver nota 138). Véase también M.T.W. ARNHEIM, The Senatorial Aristocracy in the Later Roman Empire, Oxford, 1972, espec. pp.143 ss. y G. DEPEYROT, Crisis e inflación..., pp. 106-10 y 279-81.

81 Cf. G. DEPEYROT, Crisis e inflación..., pp. 117-8 y 181-2.

82 De ahí que nos sean descritos ora como víctimas desvalidas, ora como tiranos públicos, e.g., Libanio, Orationes 47, De patrociniis 49, o Pro curiis. Los más humildes acabaron evadiendo sus responsabilidades y los más poderosos accediendo al orden senatorial, lo que motivó legislación en apariencia contradictoria: por un lado se impedía que se ordenaran clérigos (CTh XVI, 2, 3 y 7, de 320 y 330), por otro se impedía su acceso al Senado o se lo supeditaba al cumplimiento de sus deberes ciudadanos (CTh XII, 1, 48, de 361, y 1, 57-8, de 364), y, finalmente, se intentaba evitar su huida al campo (CTh XII, 1, 39, de 395). Ya que la bibliografía es amplia, nos remitirnos a A.H.M. JONES, The Later Roman Empire, 284-602: a Social, Economic and Administrative Survey, Oxford, 1973, v. I, pp. 737-57 y G. DEPEYROT, Crisis e inflación ..., pp. 30-1.

83 Sobre los vectigalia, los impuestos militares, los impuestos específicos en oro y plata y las exacciones oblaticia y coronaria, $c f$. R. DELMAIRE, Largesses sacrés ..., pp. 275-409.

84 Por supuesto, quienes se vieran obligados a comprar piezas de oro para pagar sus impuestos, sufriendo pérdidas con ello, se desquitarían subiendo el precio de sus productos. 
Para sacar la moneda buena de sus escondrijos, el Estado aplicó una legislación draconiana y premió a los cambistas, incentivándoles para comprar monedas de oro y vendérselas al Estado (solidorum venditio). ${ }^{85}$ Estas tarifas obviamente quedaron obsoletas con rapidez, y tuvieron que ser actualizadas al alza cada cierto tiempo, según el precio de mercado, ya que de otra manera nadie hubiera estado dispuesto a venderlas. ${ }^{86}$ En cualquier caso, ambas partes se entendieron, pues estaban muy interesadas en llegar a un acuerdo gracias a los considerables beneficios mutuos.

Además, con objeto de asegurar la estabilidad del flujo de ingresos del nuevo impuesto territorial (capitatio-iugatio), hizo su aparición una institución sobre la que han corrido ríos de tinta: el colonato. ${ }^{87}$ Ya con Diocleciano dejó de ser libre (295-7), y bajo Constantino tenemos la legitimación de iure de la adscripción jurídica: en octubre de $332,{ }^{88}$ recién concluida su gran campaña contra los visigodos en el curso bajo del Danubio, ${ }^{89} \mathrm{y}$ a medio camino entre las devaluaciones de 330 y 335 . La ley para los arrendatarios del Ilírico, ${ }^{90}$ donde se estipula la obligación de permanecer en la tierra, es de 371, tras la reorganización valentiniana de la moneda (vide infra).

Debido a su escaso valor, debía ser muy engorroso transportar las enormes cantidades de monedas que se precisaban para las transacciones de relativa cuantía. Con seguridad fue por ello que se introducían en cantidades determinadas en sacas selladas y garantizadas por el Estado, ahorrando el tener que contarlas, pesarlas y ensayarlas una y otra vez, y de ahí que se las llamara folles (sing. follis, "bolsa de cuero"). Podemos contemplar estos saquitos en la Notitia Dignitatum (c. 400), en la ilustración correspondiente a las insignias del comes sacrarum largitionum, ${ }^{91}$ junto a otros productos como monedas de oro y plata, bandejas de donativa, hebillas de cinturón de oro (cingula militiae), y hojas y boles de metal precioso (fig. 4).

85 Símaco. Epistolae, IX, 49; Procopio, Anecdota 25. Sobre la actividad bancaria tardoimperial, $c f$. G. DEPEYROT, Crisis e inflación..., pp. 144 ss y A. DÍAZ BAUTISTA, Estudios sobre la Banca Bizantina (Negocios bancarios en la legislación de Justiniano), Murcia, 1987.

86 Como atestigua el ilustre senador y orador Q. Aurelio Símaco -que probablemente participara en tales negocios- en un discurso del año 384 (Relationes, 29).

87 Debido a ello recomendamos a A. GONZÁLEZ BLANCO, "Bibliografía sobre el colonado romano y sus problemas", Memorias de historia antigua, 2 (1978), pp. 229-237, C. WICKHAM, Framing..., pp. 520 ss, y los breves comentarios de G. DEPEYROT, Crisis e inflación..., pp. 122-6 y 182-4. Personalmente somos afines a la heterodoxa tesis de J. M. CARRIÉ, “Colonato del Basso Impero': la resistenza del mito”, en E. LO CASCIO (ed.), Terre, proprietari e contadini dell'impero romano. Dall'affitto agrario al colonato tardoantico, Roma, 1997, pp. 96 ss (una de las más recientes de sus diversas aportaciones a tal respecto), que considera el colonato una institución fiscal, y su relación con el "modo de producción feudal" puro mito historiográfico.

${ }^{88} C T h \mathrm{~V}, 17,1$. Cf. G. BRAVO CASTAÑEDA, "El estatuto sociopolítico del colono en la génesis de la sociedad bajoimperial", Memorias de Historia Antigua, 2 (1978), pp. 59-70.

89 M. KULIKOWSKI, Rome's Gothic Wars, from the Third Century to Alaric, Cambridge, 2007, pp. 83-7.

90 Codex Iustinianus (en adelante CJ) XI, 53, 1.

91 El "conde de las liberalidades imperiales", sucesor del rationalis summa rei, era el ministro al cargo de la producción monetaria, la recaudación de impuestos y tanto el presupuesto civil como el militar. Mencionado por primera vez en el año 345 (CTh XI, 7, 5), para Alföldi el momento de creación del cargo es 324 (RIC VII, p. 20). Cf. J.P.C. KENT, “Comes Sacrarum Largitionum”, en E.C. DODD, Byzantine Silver Stamps, Washington D.C., 1961, pp. 35-45 y R. DELMAIRE, Largesses sacrés ..., pp. 25-124. 


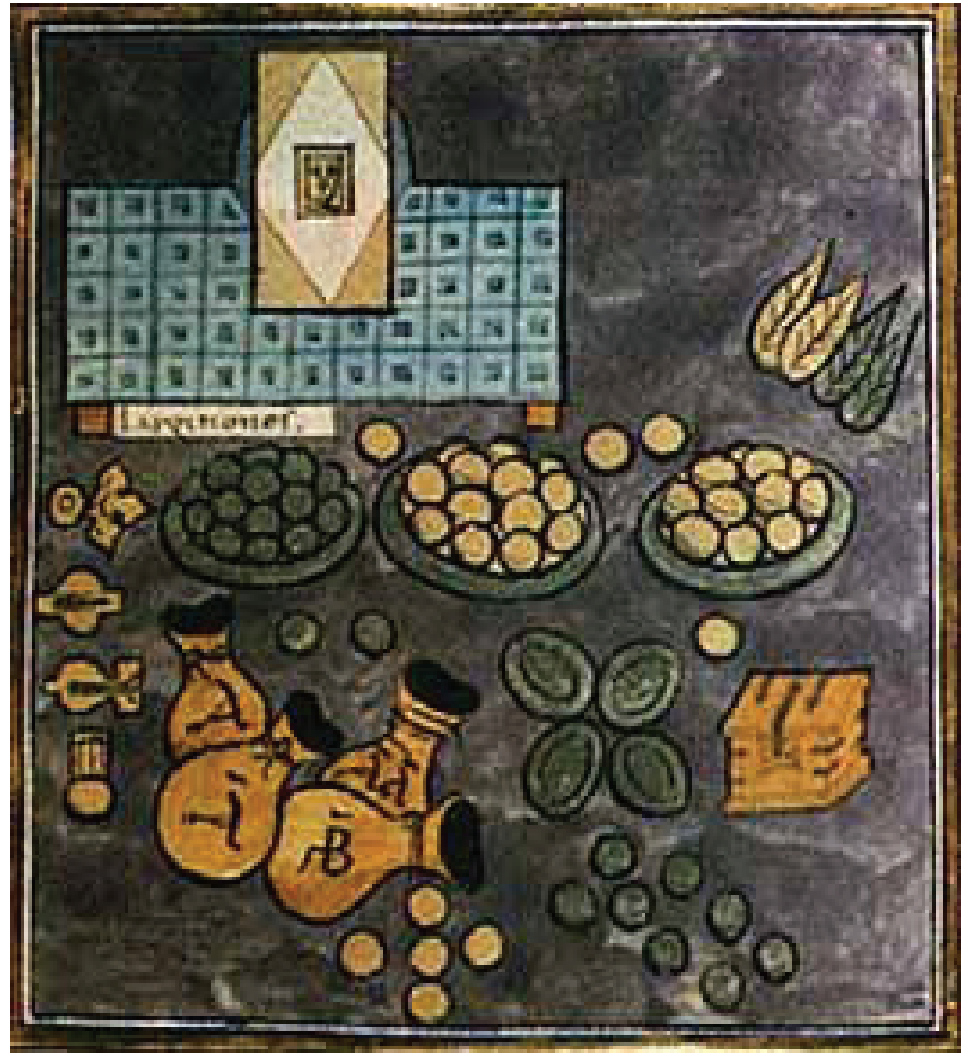

Fig. 4. Insignias del comes sacrarum largitionum en la Notitia Dignitatum. ${ }^{92}$

Incluso teniendo en cuenta esta medida, el ínfimo valor de la moneda de cobre debió hacer prohibitivo su traslado físico. Por ejemplo, al final del período que tratamos, en el año 395, un único sólido áureo de 4’4 gramos (ó 24 siliquas, 40 gramos de plata) equivalía a 7.600 nummi, los cuales pesaban nada menos que 11'4 kilogramos. De ahí la importancia de las transferencias públicas y privadas mediante mandatos o billetes convertibles en moneda, ${ }^{93}$ un sistema con precedentes en el Egipto Ptolemaico. ${ }^{94}$

Por último, cabe mencionar las más que probables secuelas de orden moral: sensación de inseguridad, pérdida de confianza en la autoridad imperial, proliferación de la actividad delictiva como único medio de sustraerse a las disposiciones estatales, histeria colectiva y atesoramiento ante cada devaluación, consumo conspicuo debido a la futilidad del ahorro, insolidaridad, etc.

92 C. NEIRA FALEIRO, La Notitia Dignitatum: nueva edición crítica y comentario histórico, Madrid, 1998, p. 294.

93 G. DEPEYROT, Crisis e inflación ..., pp. 157-8 y 296. Estos giros, siglos anteriores a las primeras letras de cambio documentadas, tienen un gran relevancia potencial a la hora de acabar de rebatir las tesis sobre la escasa monetización y poca integración económica de las distintas regiones que conformaban el Imperio. Véanse asimismo los planteamientos de W.V. HARRIS, “A Revisionist View of Roman Money”, JRS, 96 (2006), pp. 25-41, sobre la importancia del crédito en la economía romana y en el conjunto de su oferta monetaria.

94 S. von REDEN, Money in Ptolemaic Egypt, From the Macedonian Conquest to the End of the Third Century $B C$, Cambridge, 2007, pp. $254-5$ y 257, considera que no eran giros, contra lo sostenido por otros autores, p. ej. R. BOGAERT “Note su l'emploi du chèque dans l'Égypte ptolémaïque”, Chronique d'Égypte, 58 (1983), pp. 212-221, y "Banking in the Ancient World," en H. van der WEE y G. KURGAN-VAN HENTENRYK (eds.), A History of European Banking, Amberes, 2000, pp. 13-68. 


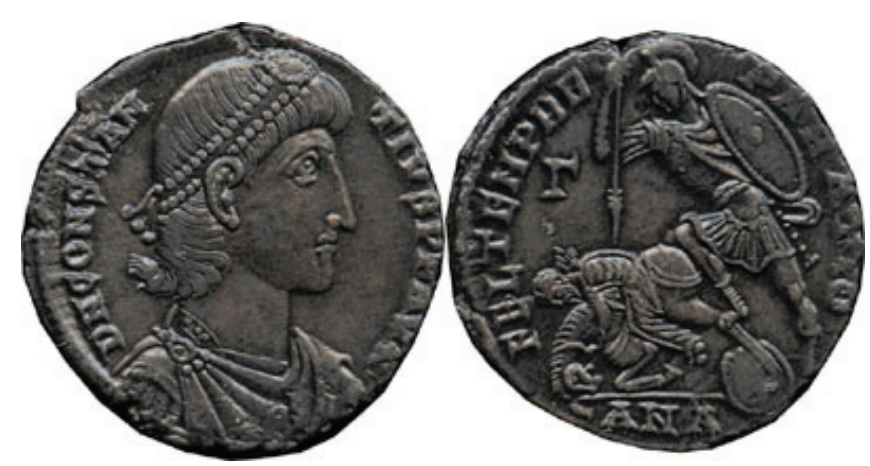

Fig. 5. Nummus antioqueno de Constancio II, tipo Fel Temp Reparatio.

En cualquier caso, de 341 a 348 el nummus era una pieza AE4 de 1'65 g $\left({ }^{1} /{ }_{196}\right)$ con un contenido de plata del $0.4 \%$. La insostenible situación económica provocó que los hermanos Constancio II y Constante emprendieran una nueva reforma monetaria en 348, la tan necesaria deflación, que coincidió con la fase final de la guerra contra Shapur II (337-50). Por motivos obvios, su realización, así como la recuperación de la confianza pública, sólo podía llevarse a cabo a través de la reacuñación masiva del vellón en circulación. Las nuevas monedas, de gran calidad artística, tenían un atractivo aspecto y lucían la optimista leyenda FEL(ix) TEMP(orum) REPARATIO, "la restauración de los buenos tiempos" (fig. 5), según tres denominaciones:

a) Una pieza grande (AE2) de 5'26 g $\left({ }_{60}\right)$ y un $3 \%$ de plata, con la marca $A$;

b) una pieza intermedia (AE3) de 4'25 g $\left({ }^{1} /{ }_{72}\right)$ y un 1'5\% de plata, con la marca $N$;

c) una pieza menor (AE4) de 2’42 g ( ${ }^{1} / 120$ ) y un 0’3\% de plata, sin marca de valor, con un fénix en el reverso, ${ }^{95}$ que parece ser el nummus precedente redivivo, con mayor peso pero menos plata.

La primera denominación, la maiorina, no debió tener el suficiente valor nominal en relación a la segunda, ya que al parecer fue fundida para extraer su plata. ${ }^{96}$ Además, debió existir una circulación diferenciada: las cecas occidentales se centraron en la denominación $A$, mientras que en Oriente -donde la vida urbana y los pequeños intercambios estaban en auge- se emitió de forma masiva la $N$.

95 Un interesante símbolo del carácter imperecedero del Imperio, así como del restablecimiento del mismo y de su moneda. Ya fue empleado en las piezas de vellón conmemorativas de las vicennalia (326) de su padre Constantino, tras la devaluación de 324, y lo cierto es que las FEL TEMP REPARATIO se aproximan sospechosamente a las decennalia de ambos hermanos (347). El fénix también aparece en un reverso habitual en las maiorinas de la misma serie, en el cual figura el Emperador en la proa de una galera pilotada por la Victoria, sosteniendo un globo con un fénix y el lábaro. Sobre la iconografía del fénix en Roma, $c f$. F. LECOCQ, "L'iconographie du phénix à Rome", Schedae, 6-1 (2009), pp. 73-106, que dedica todo un apartado a la numismática, mencionando estas monedas en concreto, así como una tercera aparición en siliquas y cobres teodosianos. Sobre estos últimos, $c f$. F. LÓPEZ SÁNCHEZ, "L'image du phénix et l'impact du désastre d'Andrinople dans la numismatique romaine", Cahiers numismatiques, 145 (2000), pp. 39-49.

\footnotetext{
96 CTh IX, 21, 6, de 349.
} 
La exitosa deflación se vio truncada por la usurpación de Magnencio (350-3) y la subsiguiente guerra civil. El victorioso Constancio II se encontró además con dificultades para absorber la moneda devaluada de aquel usurpador, a las que se unieron mayores necesidades de dinero debidas a los problemas del final de su reinado, en especial un nuevo conflicto con los sasánidas (358-63). El resultado es que se dejaron de emitir las piezas menores, cuya producción era menos rentable, y la maiorina experimentó una rápida y espectacular devaluación tanto en peso como en ley. En 350 su ley fue rebajada del 3 al 0'8\%, y en 351 su peso se redujo a 4'34 g (1/ $\left.{ }_{72}\right)$, para convertirse en 352 en una AE3 de 2'48 g $\left({ }^{1} /{ }_{120}\right)$ y un contenido de plata del 0'6\%. En 355 cayó a 2 '26 g ( $\left({ }_{130}\right)$ y 0 '5\% de plata y, finalmente, en 358, acabó convertida en una pieza de 1 '96 $\mathrm{g}\left({ }^{1}{ }_{144}\right)$, con un contenido en plata del 0 ' $1 \%$.

La resistencia a acuñar mayores cantidades, unida a la retirada de la moneda de Magnencio, agudizó la escasez de numerario propia de los períodos inflacionistas y una verdadera ola de falsificaciones e imitaciones, contra la que poco debieron servir las brutales penas recogidas en el Código Teodosiano. ${ }^{97}$ Es probable que parte de las falsificaciones e imitaciones fuera acuñada fuera del Imperio para cambiar el vellón por metal precioso y exportarlo, lo que ayudaría a explicar la presencia masiva de moneda tardoimperial en el Barbaricum ${ }^{98}$-más allá de sobornos a caciques y pagos de mercenarios- ${ }^{-99}$ así como la ley del año 374-5 prohibiendo la exportación de oro, ${ }^{100}$ explicada habitualmente con la vieja falacia de la fuga de metal precioso debido al comercio con Oriente. ${ }^{101}$

Juliano el Apóstata (361-3) practicó un nuevo arbitrio deflacionista, con una reacuñación y la introducción de una moneda de mayor tamaño y peso, pero menos plata que su precedente de 348 (AE1 de 8'13 g y 2\% de plata; fig. 6), y una fracción prácticamente de cobre (AE3 de 2’87 g y 0 ' $1 \%$ ). Ambas eran de una factura y una calidad artística excelentes. El nuevo sistema tuvo una breve pero exitosa existencia, ${ }^{102}$ hasta acabar hundido por el desastroso final de la campaña persa

97 K.W. HARL, Coinage ..., p. 167-71. Si atendemos a las enormes cantidades de moneda falsa que aún día se encuentran en yacimientos, los usuarios de las mismas debieron estar autorizados a reacunarlas o a emplearlas reconociendo su valor inferior. Lo que probablemente mantuvo a raya la falsificación fue el propio abismo de la devaluación, al hacerla cada vez menos rentable. $C f$. P. BASTIEN (1985) "Imitations of Roman Bronce Coins, A.D. 318-363”, en American Numismatic Society Museum Notes 30, pp. 143-177, y M.F. HENDY, Studies..., pp. 320-8.

98 Un fenómeno similar al observado por Pedro de Oña o Francisco de Quevedo en la España del s. XVII. Sobre la moneda imperial más allá del limes, cf. J. CHAMEROY, “Comment les monnaies romaines étaient-elles exportées sous l'Empire? L'exemple du moyen Danube”, Histoire \& Mesure, 17-3/4 (2002), pp. 43-78, D. MOISIL, "The Danube Limes and the Barbaricum 294-498. A Study in Coin Circulation", Histoire \& Mesure, 17-3/4 (2002), pp. 79-120, y A. GÂNDILA "Face Value or Bullion Value? Early Byzantine Coins beyond the Lower Danube Border", en M. WOLOSZYN (ed.), Byzantine Coins in Central Europe between the 5th and 10th Century, Cracovia, 2009, pp. 449-471.

99 El tema tiene mucha enjundia y no lo podemos desarrollar aquí. Baste mencionar que H. ELTON, Warfare..., pp. 134-52, ha demostrado que sólo un 30\% de los componentes de los auxilia palatina eran de origen bárbaro -cifra mucho menor en el caso de los oficiales- aun cuando se supone que eran las unidades más "barbarizadas" del ejército romano.

100 CJ IV, 63, 2, de 374-5.

101 Según Plinio, Naturalis Historia XII, 41, 84, se perdían 100 millones de sestercios al año en el comercio con Oriente debido al ansia romana de seda. Esta vieja fábula mercantilista, la obsesión con una balanza comercial positiva, parte de la ancestral falacia que identifica el medio de intercambio, el dinero, con la riqueza en sí. Recordemos la Ley de Say, falsamente refutada por Keynes, según la cual, en última instancia, las mercancías no se pagan con dinero, sino con otras mercancías. El dinero es solamente el intermediario. Sobre el comercio con Oriente y la moneda, $c f$. K.W. HARL Coinage..., p. 299-307.

102 Aun así hubo resistencias debido a su simbología pagana, lo que viene a demostrar de nuevo hasta qué punto 

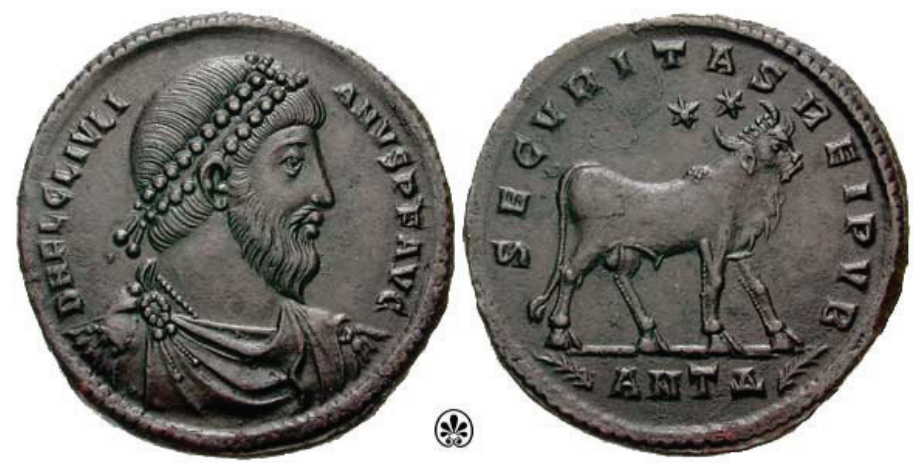

Fig. 6. Maiorina antioquena de Juliano el Apóstata, tipo Securitas Reipublicae.

de Juliano y las turbulencias que siguieron a su muerte. Sus sucesores, Joviano y Valentiniano siguieron acuñando unas maiorinas completamente devaluadas (c. 0’4-0’2\% de plata) hasta 367.

Tras un período de aparente cese de la emisión de moneda, a partir de 369, bajo Valentiniano y Valente (364-78), deja de acuñarse vellón, y la calderilla pasa a ser exclusivamente cobre, empleándose la plata extraída en la acuñación de argénteos. El nuevo nummus era un modesto AE3 de 2’25 g.

En 379 los emperadores Graciano (375-83), Valentiniano II (375-92) y Teodosio (379-95) intentaron un nuevo arbitrio deflacionista replicando la reforma de 348, con un AE2 de 5'25 g $\left({ }^{1} /{ }_{60}\right)$, llamado decargyrus, un AE3 de 2’45 g $\left({ }^{1} / 120\right)$, que fue el que mayor difusión tuvo en Oriente, y un AE4 de tan sólo 1'5 g ( $\left.{ }^{1 / 192}\right)$, llamado nummus centenionalis. Sin embargo, el nuevo sistema apenas perduró cinco años. Las usurpaciones de Magno Máximo (383-8) y Eugenio (392-4) y las campañas de Teodosio contra ambos produjeron nuevas devaluaciones del cobre. Máximo emitió de forma masiva el AE4 y Teodosio cesó la acuñación de las mayores denominaciones (388-92), para acabar desmonetizándolas y convirtiendo al centenional en el único curso legal de cobre $(395){ }^{103}$
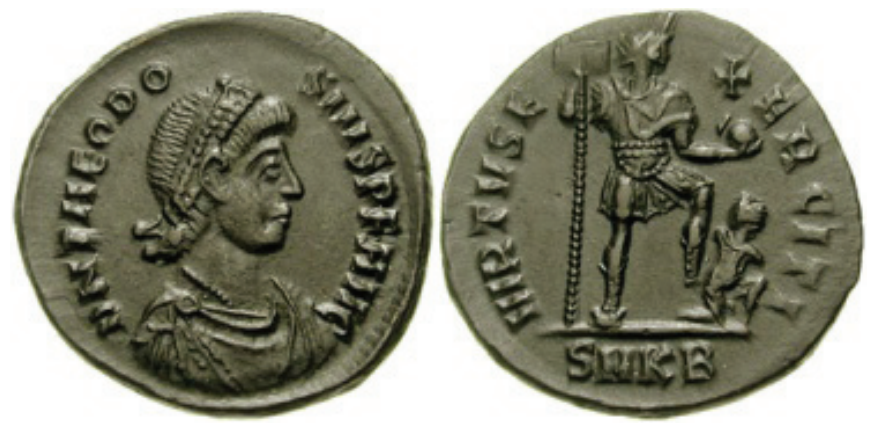

Fig. 7. Nummus cyziceno de Teodosio el Grande, tipo Virtus Exerciti.

el dinero está sometido a valores subjetivos. Sócrates Escolástico (Historia Ecclesiastica III, 17) registró la oposición de la cristiana población antioquena, con la que tantos roces tuvo Juliano (Amiano XXII, 12-14), a su moneda por mostrar un toro en el reverso (fig. 6). Sobre la iconografía de Juliano, su problemática y debates al respecto, $c f$. F.D. GILLIARD, "Notes on the Coinage of the Julian, the Apostate", JRS, 54 (1964), pp. 135-142, F. MARCO SIMÓN, "Ambivalencia icónica y persuasión ideológica: las monedas de Juliano con representación del toro", Athenaeum, 87-1 (1999), pp. 201-14, y Ma del M. ROYO MARTÍNEZ, "El emperador Juliano II y el programa iconográfico de sus monedas", Documenta et instrumenta, 7 (2009), pp. 161-186.

103 CTh IX, 23, 2. 


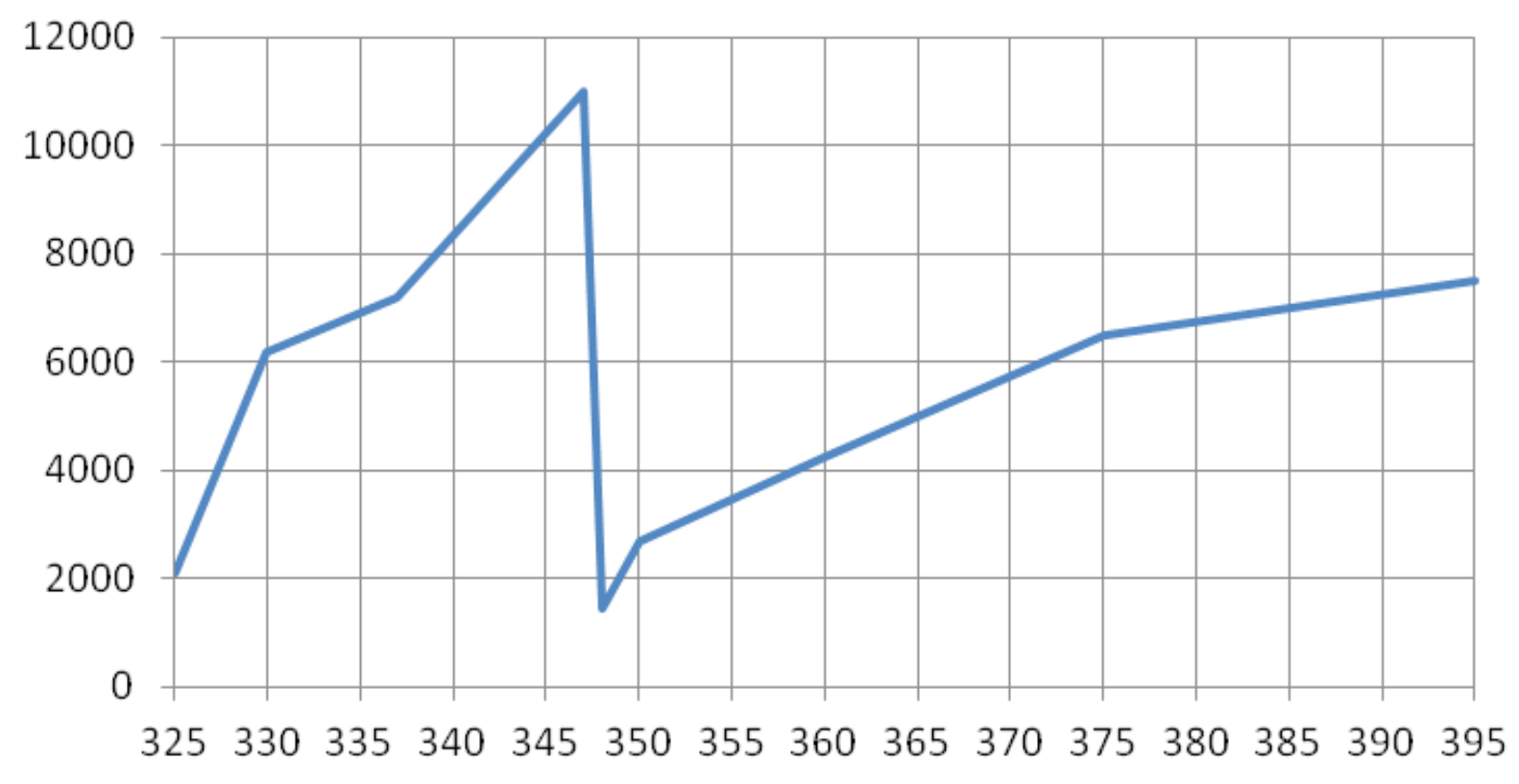

A juzgar por el antecedente gráfico mostrando las equivalencias entre el sólido y el nummus (325-95),${ }^{104}$ la reforma de 348 paró en seco la acelerada inflación. A partir de entonces, y a pesar de su fracaso y la vuelta a la devaluación del vellón, la subida fue mucho más moderada. George Depeyrot calcula una subida de precios mucho más moderada entre 369 y 395 que en la época precedente, en torno al 3\% anual. ${ }^{105}$ Ello se debió al cese de la acuñación de vellón y, como veremos a continuación, la exitosa reintroducción de la moneda de plata.

\subsection{La evolución de la plata en el siglo $I^{106}$}

El argénteo fue escasamente producido bajo Diocleciano. Para 300 su acuñación había cesado excepto en Tréveris, Roma, Siscia y Tesalónica, que emitieron de forma esporádica hasta 305, y Serdica, que perseveró hasta 307. ${ }^{107} \mathrm{Su}$ fracaso vino determinado no sólo por la ley de Gresham, sino por la propia dinámica de las necesidades financieras del Estado, para el cual era mucho más rentable emplear el metal precioso en acuñar vellón de forma masiva. Su producción no se reanudó hasta que Constantino lo reintrodujo a partir de 320, acompañado de los llamados miliarenses, ligero y pesado -con una talla de 72 y 60 por libra, respectivamente- y de una serie de múltiplos aún mayores. Las denominaciones y los tipos carecían de cualquier uniformidad. Se trataba de monedas de escasísima circulación, acuñadas para ser distribuidas como regalo o donativo en ocasiones especiales, de gran interés, pero sin mayor relevancia para nuestro trabajo.

104 K.W. HARL, Coinage..., p. 168.

105 G. DEPEYROT, Crisis e inflación..., pp. 132-4.

106 RIC VI, p. 93; VII, pp. 4-8; VIII, pp. 57-9; IX, pp. xxvii-iii; C.E. KING, Roman Silver Coins vol. V, Carausius to Romulus Augustus, Londres, 1987.

107 C.E. KING, “The Fourth Century...,", p. 10. 
No fue hasta el año 355 que Constancio II -dueño ya de todo el Imperio- restableció la producción del argenteus a gran escala (Fig. 8). Su talla se redujo de 96 a 144 por libra con un peso aproximado de $2 \mathrm{~g}$. El señoraje sería así de 0’25 g, el 11’5\%. Sus múltiplos se ajustaron al nuevo peso, y su pureza se ciñó a lo que, andado el tiempo, sería el estándar sterling (92'5\%). Se cree que su equivalencia era de 24 por sólido, según la definición de San Isidoro de Sevilla, ${ }^{108}$ a la que se suma la evidencia numismática. Resulta evidente de dónde procedió el metal necesario para acuñar plata en tales cantidades: de las inmensas oleadas de vellón envilecido que se desmonetizaron con la reforma de 348 .
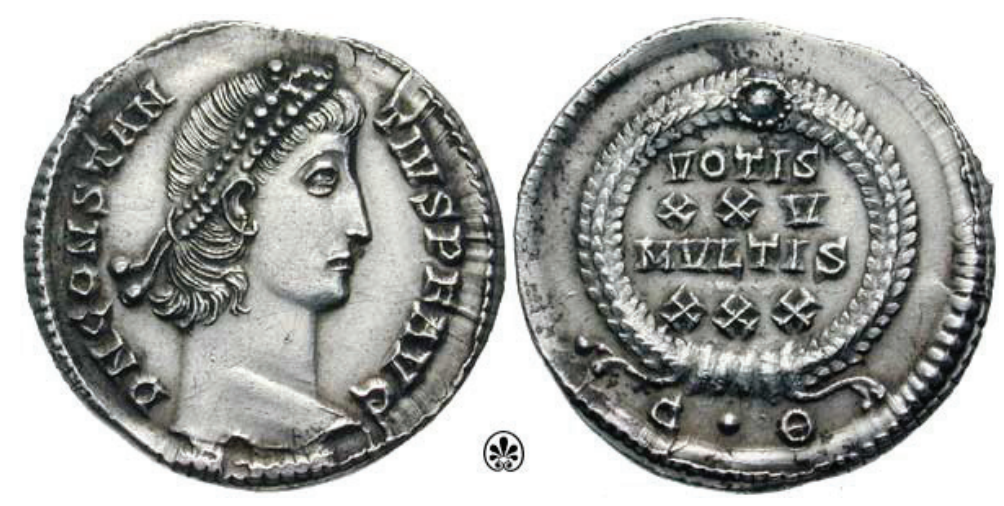

Fig. 8. Siliqua constantinopolitana de Constancio II, tipo votivo.

Debió existir, posiblemente, una resistencia a producir moneda de plata pequeña, al ser menos rentable, exigir más tiempo y trabajo, y resultar más gravosos los pagos que se realizaran con ella, lo que perjudicaría al Estado en sus grandes desembolsos. Pese a ello, la reforma de Constancio fue un éxito completo: el nuevo argénteo convirtió en el principal circulante medio del Imperio. ${ }^{109}$ El motivo para ello no es ningún misterio: se trataba de una moneda de calidad pero menor que el argénteo tetrárquico y constantiniano, que podía emplearse en transacciones menudas, y cuya introducción vino acompañada por la deflación del vellón, al absorberse grandes cantidades de la moneda vil de Magnencio, lo que evitó que saliera de circulación.

Tras ser devaluada por el propio Constancio y su sucesor Juliano, los Valentinianos restablecieron la siliqua, empleando en ello la plata obtenida al cesar la acuñación del vellón. Es notorio el empeño de los Valentinianos y de Teodosio el Grande en no devaluarla a pesar de las acucian-

108 Isidoro de Sevilla, Etymologiarum XVI, 25.

109 K.W. HARL, Coinage..., pp. 172-3. Por primera vez en más de 150 años los romanos dispusieron de una moneda de plata que utilizar en su vida diaria y atesorar. El famoso tesoro de Hoxne, descubierto en Suffolk en 1992 y fechado como muy tarde hacia 450, contenía 580 solidi (540 del período 388-408) y 24 bronces frente a 60 miliarenses y 14.565 siliquas y 5 medias siliquas, la mayor colección del mundo romano. Ello ha contribuido de forma decisiva a nuestro conocimiento sobre esta moneda, $c f$. P.S.W. GUEST, The Late Roman Gold and Silver Coins from the Hoxne Treasure, Londres, 2005. Parece que los tesoros de plata abundan especialmente en Britania y el curso bajo del Danubio. A tal respecto, y sobre tesoros tardoimperiales en general, $c f$., R.A.G. CARSON, J.P.C. KENT y A.M. BURNETT, RIC X, Londres, 1994, pp. 1xxxi-clxxviii. No obstante, que en Oriente haya poco atesoramiento de plata puede deberse al menor peligro en la zona, y a la mayor disponibilidad de sólidos, puesto que las cecas orientales producían en torno al $80 \%$ de las emisiones de oro. 
tes necesidades generadas por la Gran Conspiración en Britania (367-8), ${ }^{110}$ la guerra gótica de 367-69, ${ }^{111}$ la usurpación de Firmo en África (372-5), ${ }^{112}$ una invasión alamana ${ }^{113} \mathrm{y}$, en especial, la Guerra Gótica (376-82), con el exterminio del ejército de Valente en Adrianópolis y su costosísima reconstrucción. ${ }^{114}$ No es hasta la usurpación de Máximo que finalmente fue reducida a una talla de 168 por libra (1'9 g), mantenida por Teodosio y reducida de forma definitiva a 196 (1'6 g) bajo el imperio de sus hijos Arcadio y Honorio, en 397. ${ }^{115}$ Pese a ello siguió constituyendo el circulante medio por excelencia durante todo el siglo V.

\subsection{La evolución del oro en el siglo IV ${ }^{116}$}

Tras interrumpirse su acuñación con la crisis de 306, Constantino introdujo en 309 un sólido áureo de extraordinaria pureza (99'7 \%) y una talla de 72 por libra, ${ }^{5} / 6$ de su homólogo tetrárquico. Con un peso estándar de 4'4 g., la diferencia de 0'14 g con respecto al teórica supone un señoraje del $3 \%$, un $0 ’ 25 \%$ más que el precedente.

El sólido constantiniano tuvo un enorme éxito, al contrario que su predecesor, aunque debido a su enorme valor debemos entender que su circulación fue limitada. La acuñación de oro a gran escala fue posible al apropiarse Constantino de los erarios de sus enemigos, y en particular de los enormes tesoros hasta entonces sepultados en los templos paganos, que liberó con su conversión al Cristianismo. ${ }^{117}$

Se trató de una moneda estable y acreditada que constituyó la piedra angular del sistema monetario: una divisa internacional de referencia, aceptada en todos los países extranjeros, ${ }^{118}$ así como un elemento del máximo prestigio para el Emperador de los Romanos, cuya efigie garantizaba su calidad. ${ }^{119}$

110 Cf. A.R. BIRLEY, The Roman Government of Britain, Oxford, 2007, pp. 427-40.

$111 C f$. N. LENSKI, Failure of Empire. Valens and the Roman State in the Fourth Century AD, Berkeley, 2002, pp. 127-37.

112 Cf. J.F. MATTHEWS, Western Aristocracies and Imperial Court, A.D. 364-425, Nueva York, 1975, p 93.

113 Amiano Marcelino, Res Gestae XV, 4 y XXXI, 10.

114 La fuente principal es el libro XXXI de Amiano Marcelino, y entre las obras más modernas destacamos P. HEATHER, La caída del Imperio Romano, Barcelona, 2006, pp. 209-46, y M. KULIKOWSKI, Rome's Gothic Wars..., pp. 123-53.

115 K.W. HARL, Coinage ..., p. 173

116 RIC VII, pp. 1-4; VIII, pp- 55-7; IX, pp. xxvi-vii; J. P. C. KENT "Gold Coinage in the Later Roman Empire", en Essays in Roman Coinage presented to Harold Mattingly, Oxford, 1956, pp. 190-204; G. DEPEYROT, "L'or et la société du Bas Empire (IVe-Ve siècles)", Numisma, 180-185 (1993), pp. 81-116.

$117 D R B$ II, 1. Cf. C. BUENACASA, "La decadencia y cristianización de los templos paganos a lo largo de la Antigüedad Tardía (313-423)”, Polis, 9 (1997), pp. 25-50. Sus patrimonios inmuebles también pasaron al Estado, cf. B. ENJUTO SÁNCHEZ, "Las disposiciones judiciales de Constantino y Juliano a propósito de las tierras de los templos paganos", Gerión, 18 (2000), pp. 407-423.

118 Cosmas Indicopleustés afirmaba hacia 550 que todas las naciones conducían su comercio con el sólido, lo aceptaban, y lo admiraban; $c f$. M.F. HENDY, Studies..., pp. 276-8. El sólido fue muy apreciado y atesorado en la India e incluso imitado por el dinar sasánida (K.W. HARL, Coinage ..., pp. 308-9).

119 Así por ejemplo, Procopio (Guerras VII, 33, 5-6) cuenta que Teudeberto de Austrasia intentó emitir sólidos con su propio retrato en 537, pero que no fueron aceptados, ya que para considerarse sólido debía lucir la imagen del Emperador. 
El sólido contaba con una serie de múltiplos, los llamados "medallones", grandes monedas de prestigio valoradas en $1 \mathrm{y}^{1 /}{ }_{5}, 1 \mathrm{y}^{1 /}, 2,3,4 \mathrm{y}{ }_{2}^{1 / 2}$, y hasta 9 y 12 sólidos (unas impresionantes piezas de 40'5 y $54 \mathrm{~g}$ de oro puro, respectivamente), destinadas a regalos y donaciones. ${ }^{120}$ Con respecto a las fracciones, se hallaban por un lado el semis o medio sólido ( 2 ’25 g; ${ }^{1 / 144}$ ), y por otro el scripulum, en apariencia $3 / 8$ de sólido $\left(1 ’ 65 \mathrm{~g} ;{ }_{1}^{1 /}{ }_{192}\right)$ ó 9 siliquas, por extraño que pueda resultar. Al final del período, bajo Máximo y Teodosio se incorporó la moneda de un tercio, el tremise, con un peso de 1 '5 $\mathrm{g}\left(1_{216}\right)$. Emitida a gran escala durante el siglo $\mathrm{V}$, tuvo un enorme éxito, ya que su menor valor la hacía más apta para los intercambios de menor cuantía, y por tanto más accesible para un mayor sector de la población.
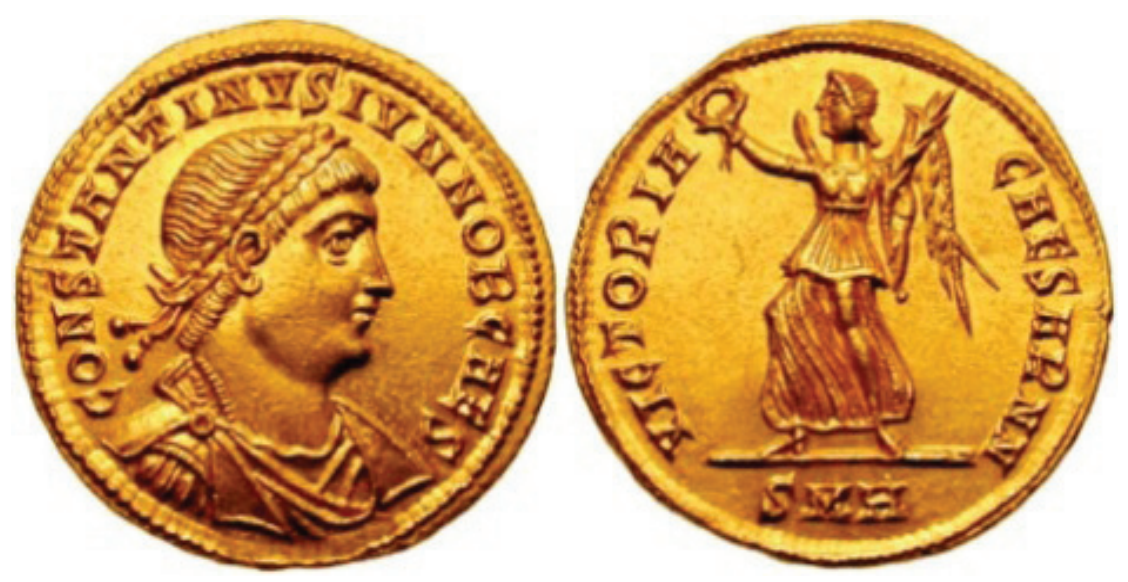

Fig. 9. Sólido heracleota de Constantino II como césar.

Dominando el comercio a larga distancia, los pagos militares, los donativa y los intercambios de alto nivel, la alteración del sólido hubiera supuesto graves contratiempos al funcionamiento financiero del Estado, además de un profundo desprestigio de la dignidad imperial, de modo que su devaluación fue muy reducida, y sólo se produjo en los momentos de máxima necesidad: bajo Constantino se redujo al 97'7 en 323, en plena lucha contra Licinio, y para 366 había caído al 95 $\%$, debido a la terrible crisis que se produjo al final de la dinastía constantiniana y durante el ascenso al poder de la valentiniana. Una ley de 343 -año de la exitosa campaña de Constancio II en Adiabene-pone de manifiesto los graves problemas provocados incluso por tan leve devaluación, disponiendo que todos los sólidos debían ser aceptados al mismo valor, con independencia de su contenido de oro, y su recorte o falsificación penados con la muerte. ${ }^{121}$ A pesar de tales disposiciones, se generalizó la falsificación, y está documentado que en esta época incluso los funcionarios del Erario pasaban moneda falsa. ${ }^{122} \mathrm{~A}$ fin de aliviar tal problema, se decretó que el producto de los impuestos debía ser fundido -ya que así era más simple comprobarlo-y conducido en un plazo de diez días a la tesorería de la sede imperial (comitatus) más cercana, donde sería acuñado en forma

120 La coexistencia de grandes monedas de prestigio en metal precioso con un circulante de vellón completamente envilecido (al que Quevedo trataba en El chitón de las Tarabillas de "peste acuñada") constituye un curioso paralelismo con la España del siglo XVII. Sobre el tema, $c f$. J. de SANTIAGO FERNÁNDEZ, Política monetaria en Castilla durante el siglo XVII, Valladolid, 2000.

121 CTh IX, 22, 1.

122 CTh XII, 6, 12 y 13, de 366 y 367. 
de nuevos solidi por los "fabricantes de sólidos" (aurifices solidorum). ${ }^{123}$ Esta práctica debió seguramente acentuar la tendencia de la moneda de oro a permanecer en circulación por poco tiempo y en círculos reducidos. Restaurado a los 4'4 g. y el 99'7 \% de pureza por Valentiniano y Valente en 367/8, el sólido permaneció inalterado durante los siguientes 700 años.

No hubo, por tanto, inflación en la moneda áurea, pues apenas se devaluó y siempre disfrutó de la máxima confianza del público. Incluso la variación de la cantidad de oro disponible debió ser mínima. ${ }^{124}$ Prueba de todo ello es que la estabilidad de los precios expresados en el dorado metal es casi total. ${ }^{125}$ Contra lo afirmado por el anónimo de rebus bellicis, y asumido de forma acrítica por historiadores como Santo Mazzarino, ${ }^{126}$ no fue no la circulación del oro puesta en marcha por Constantino, sino las ingentes cantidades de vellón en circulación y sus constantes mutaciones de peso, ley y valor nominal, las que verdaderamente sembraron el caos. ${ }^{127}$

Jairus Banaji sostiene que la implementación del sólido alimentó una ola de prosperidad en el siglo IV. ${ }^{128}$ No obstante, este autor yerra por no comprender el concepto de inflación y, siguiendo la estela del anónimo de rebus bellicis, Mickwicz y Mazzarino, otorgando el papel primordial a la moneda de oro. Si bien es cierto que su restauración es importante, el verdadero hito de los siglos III y IV fue la sustitución del circulante medio de plata por un vellón cada vez más envilecido, y las consecuencias que de ello se derivaron, como acabamos de ver. La gran expansión económica de ciertas regiones durante el siglo IV no fue tanto producto del sólido como de los estímulos inflacionistas del vellón, por un lado, y por otro la exitosa reintroducción de la moneda de plata -la primera en 150 años- por parte de Constancio II, Juliano y los Valentinianos, ya en la segunda mitad del siglo.

\section{POLÍTICA Y REACUÑACIONES}

Que el ejército representaba la principal partida de gastos del Imperio Romano, en especial en época tardía, es un hecho contrastado. ${ }^{129}$ Hugh Elton ha establecido que, entre soldadas, equipo y mantenimiento, el total del ejército debía oscilar entre los 3.415.500 y 6.831 .000 sólidos anuales al filo del siglo $\mathrm{V}$, con unos efectivos de entre 300.000 y 600.000 hombres. ${ }^{130}$ Las estimaciones de Warren Treadgold -que considera que se valoran las pagas muy a la baja-son de 7.647.000 solidi, el $81 \%$ del presupuesto, bajo Diocleciano y con un ejército de $350.000 .{ }^{131}$

123 CTh X, 24, 3, de 381 .

124 Vide nota 34.

125 Hecho que ya apreció en su día O. SEECK, Geschichte des Untergangs der Antiken Welt, Berlín, 1909.

126 S. MAZZARINO, Aspetti sociali del quarto secolo. Richerche di storia tardoromana, Roma, 1951, espec. pp. 110 ss.

127 Como destaca F. de MARTINO, Historia económica ..., pp. 454-5. Ya E. FREZOULS, “A propos de la hausse des prix sous Dioclétien”, Mélanges Carcopino, París, 1966, pp. 377-396, apreciaba que la causa de la inflación había de buscarse en la moneda de vellón.

128 J. BANAJI, Agrarian Change..., espec. pp. 213-21.

129 W. TREADGOLD, Byzantium and Its Army, 284-1081, Stanford, 1995, pp. 166-7 y 195-7.

130 H. ELTON, Warfare in Roman Europe 350-425, Oxford, 1996, pp. 118-127.

131 W. TREADGOLD, Byzantium..., p. 195. La cifra está convertida a sólidos a efectos comparativos, y se acercan a los 235 millones de denarios en que K.W. HARL, Coinage..., pp. 218-9, estima el coste del ejército hacia 230 . 
Ahora bien: eso en tiempo de paz. Las campañas y las movilizaciones del ejército comitatense eran increíblemente costosas, más aún en el caso de campañas navales. Por ejemplo, la mayor y más costosa de las que tenemos noticia fue la fallida expedición dirigida por Basilisco en 468 contra los vándalos. Si hemos de creer a Juan Lido y a Procopio, estaba formada por 100.000 soldados, 300.000 marinos y 1.000 naves, y costó la friolera de 9.360 .000 solidi, pues el emperador León fue "extraordinariamente generoso" con los soldados y los remeros. ${ }^{132}$ Aun cuando tan abultada cifra incluyera las soldadas regulares, la campaña consumió los 7'2 millones acumulados por el finado emperador oriental, Marciano, y otros 2 del colega occidental de León I, Antemio. ${ }^{133}$

Parece lógico que suponer que los costes de las grandes guerras civiles de la época no debieron ir muy a la zaga. Por ejemplo, en 323-4 Constantino movilizó un ejército de 150.000 hombres y 4.000 naves contra Licinio. ${ }^{134} \mathrm{E}$ incluso el coste de las campañas ordinarias seguía siendo considerable. Treadgold estima que la de 533-4 contra los vándalos -formada por 17.000 soldados y 500 transportes y 92 naves de guerra con un total de 32.000 tripulantes- costó 1.100 .000 sólidos. ${ }^{135}$ En 719 el khan búlgaro Tervel recibió 360.000 del depuesto Anastasio II para financiar la fallida campaña con la que intentó recuperar su trono. ${ }^{136}$ Para este autor, el coste habitual de una campaña estaría en torno a los 300.000. ${ }^{137}$

A la hora de intentar establecer los ingresos del Imperio y determinar el peso del gasto militar, casi nuestro único recurso es una ley de Valentiniano III, según la cual Numidia tributaba 78.200 sólidos y la Mauritania Sitifensis 41.000. ${ }^{138}$ Hugh Elton considera a Numidia una provincia "pobre", y la emplea como media: 120 provincias x 72.000 sólidos $(1.000$ libras $)=8.640 .000$ sólidos. ${ }^{139}$ Más allá de la excesiva simpleza del cálculo, ${ }^{140}$ lo cierto es que se aproxima a las estimaciones de Treadgold, que habla de un presupuesto de 9.441 .000 solidi anuales, con un superávit en torno a 800.000 , cifras que más o menos cuadran con los datos que tenemos de las reservas acumuladas por varios emperadores. ${ }^{141}$

132 Juan Lido, De Magistratibus III; Procopio, Guerras, III, 6, 1-2.

133 M.F. HENDY, Studies..., pp. 221. Se supone que la reserva venía acumulándose desde el fracaso de la campaña de Mayoriano contra los vándalos, en 461, lo que nos da un considerable superávit anual de más de 300.000 solidi para el disminuido Imperio Occidental en su fase final, y eso a pesar de la actividad militar de los patricios Ricimero y Marcelino, si bien es cierto que los gastos de los menguantes ejércitos occidentales también debían ser menores. Aunque las cifras de esta campaña parezcan exageradas, lo cierto es que cuadran, cf. W. TREADGOLD, Byzantium..., pp. 189-91.

134 Zósimo, Historia Nova, II, 22-26.

135 W. TREADGOLD, Byzantium..., p. 191-2.

136 Teófanes, Crónica AM 6211.

137 Viendo, pues, lo cara que es la guerra, quizá no debiera merecernos un juicio tan negativo que el Imperio de Oriente prefiriera darle algo de calderilla a los hunos entre 422 y 450 para que no incordiaran: un total de 1.335 .600 sólidos a lo largo de un período de veintiocho años (K.W. HARL Coinage ..., p. 310).

138 Novellae Valentiniani (en adelante, Nov. Val.) 13, de 21 de junio de 445, que tras la ocupación vándala reducía las cargas fiscales de ambas provincias a $1 \frac{1}{8}$ (9.775 y 5.125 solidi, respectivamente).

139 H. ELTON, Warfare..., pp. 119-20.

140 El problema es que Numidia no era "pobre", sino una importante región agrícola. Quizá fuera menos rica y orientada a la exportación que sus vecinas orientales, el África Proconsular y la Byzacena, pero era extensa y próspera. Pretender que provincias paupérrimas y diminutas como los Alpes Marítimos tributaran una suma parecida, incluso aunque se pretenda compensar de tal modo el ingreso extraordinario de diócesis tan ricas como Egipto (20.000 libras de oro bajo Justiniano), resulta muy cuestionable.

141 W. TREADGOLD, Byzantium..., p. 195. 
Comparando las fechas de las devaluaciones del vellón con la historia política, observamos un vínculo evidente, aunque no una causalidad mecánica, entre las devaluaciones del vellón y la actividad bélica, especialmente en el caso de las usurpaciones y las guerras civiles, que sintetizamos en el siguiente cuadro:

\begin{tabular}{|c|c|}
\hline 294 & $\begin{array}{l}\text { Guerra persa de Diocleciano; campañas en el Rin y el Danubio; campañas contra los usurpadores Carausio } \\
\text { y Alecto en Britania. }\end{array}$ \\
\hline 307 & $\begin{array}{l}\text { Quiebra del sistema tetrárquico; usurpación de Majencio en Italia y África; fallida campaña de Flavio } \\
\text { Severo contra Majencio; invasión franca en el Rin. }\end{array}$ \\
\hline 310 & $\begin{array}{l}\text { Campaña de Majencio contra el usurpador Domicio Alejandro en África; Constantino se proclama } \\
\text { Augusto; enfermedad de Galerio. }\end{array}$ \\
\hline 313 & Guerra entre Constantino y Majencio en Occidente; guerra entre Licinio y Maximino Daia en Oriente. \\
\hline 318 & Guerra entre Constantino y Licinio. \\
\hline 324 & Lucha final entre Constantino y Licinio. \\
\hline 330 & $\begin{array}{l}\text { Construcción de Constantinopla; campañas de Constantino contra los sármatas y los godos en el limes } \\
\text { danubiano. }\end{array}$ \\
\hline 335 & Dificultades en Oriente; los persas instalan un títere en el trono de Armenia. \\
\hline 337 & Preparativos de la abortada campaña persa de Constantino; los sasánidas invaden el Imperio. \\
\hline 341 & $\begin{array}{l}\text { Campaña de Constantino II contra Constante; continúa la guerra persa en Oriente; campañas contra los } \\
\text { francos en el limes renano. }\end{array}$ \\
\hline 350-1 & Usurpaciones de Magnencio y Decencio en Occidente y de Vetranio en Mesia. \\
\hline 352 & $\begin{array}{l}\text { Invasión de francos y alamanes en el limes renano; represión de la revuelta judía en Palestina; preparativos } \\
\text { de la campaña de Constancio II contra Magnencio. }\end{array}$ \\
\hline 355 & $\begin{array}{l}\text { Usurpación de Silvano en la Galia; invasión de francos y alamanes en el limes renano y danubiano; } \\
\text { amenaza sasánida en Oriente. }\end{array}$ \\
\hline 358 & $\begin{array}{l}\text { Campaña de Constancio II en el Danubio contra sármatas y cuados. Campañas de Juliano en el limes } \\
\text { renano. }\end{array}$ \\
\hline 364-7 & $\begin{array}{l}\text { Fracaso de la campaña persa de Juliano, paz gravosa ante los sasánidas, usurpación de Procopio en } \\
\text { Constantinopla. }\end{array}$ \\
\hline 383 & Usurpación de Magno Máximo en Occidente. \\
\hline 388 & Campaña de Teodosio contra Máximo; invasión franca en el limes renano. \\
\hline 395 & Reconstrucción del ejército tras la campaña de Teodosio contra el usurpador Eugenio en Occidente. \\
\hline
\end{tabular}

Para todo usurpador - como los propios Constantino y Juliano- era preciso obtener de inmediato reconocimiento público y recaudar fondos con los que sostener su causa, pues a ellos y sus partidarios les iba la vida en ello. ${ }^{142}$ Elevar los impuestos era un recurso muy poco propicio para ganarse el apoyo popular, de modo que obtenían fondos a través de confiscaciones -en especial de su rivales políticos- y la reacuñación de moneda. Así por ejemplo, nos consta que uno de los

142 Sobre la práctica de la usurpación en el siglo IV, $c f$. A. WARDMAN, "Usurpers and Internal Conflicts in the Fourth Century AD”, Historia, 33 (1984), pp. 220-37, A. ALBA LÓPEZ, Príncipes y tiranos. Teología politica y poder imperial en el siglo IV d.C., Madrid, 2006, pp. 41 ss., y M. HUMPRHIES, "From Usurper to Emperor: The Politics of Legitimation in the Age of Constantine", Journal of Late Antiquity, 1-1 (2008), pp. 82-100. 
primeros actos del usurpador Procopio (365-66) fue acuñar piezas de oro con su nombre y efigie, a fin de legitimar su posición. ${ }^{143}$

Por tanto, está meridianamente claro que la inflación era una vía de ingreso complementario a unas imposiciones fiscales insuficientes para hacer frente a cuantiosos gastos derivados de los numerosos conflictos bélicos. Contra las estimaciones de que el Imperio estuvo siempre sobrado de fondos, ${ }^{144}$ el argumento de pura lógica es que, de haber resultado suficiente la recaudación regular, el gobierno imperial no se hubiera visto compelido a devaluar la moneda.

La manipulación de la moneda no era un capricho más de unos déspotas que no conformaban con aplastar al pueblo romano bajo una fiscalidad insoportable, sino el resultado de unas acuciantes necesidades militares que se juzgaban mucho más importantes para la salvaguardia del Imperio que las consecuencias que podía tener la inflación a medio o largo plazo. Se trataba de un medio cómodo de obtener fondos de forma que no pareciera que se extraían del bolsillo del contribuyente, sometido en época tardoimperial a unas cargas impositivas que, aun dando margen a la exageración de las fuentes, son descritas siempre como extremadamente gravosas y tremendamente impopulares. ${ }^{145}$ El Estado no sólo se beneficiaba de un mayor señoraje, sino que, con cada reacuñación, extraía la plata de las monedas y obtenía cuantiosas ganancias, devolviendo más y más cobre a los particulares, que lógicamente se resistían a esta práctica.

El recurso a la alteración de la moneda dependería, naturalmente, del coste y duración de las operaciones y de los recursos disponibles. ${ }^{146}$ Se percibe con claridad que el peor período de devaluación, el reinado de treinta años de Constantino el Grande, durante el cual el vellón se infló nada menos que en ocho ocasiones, estuvo marcado por continuas guerras civiles y exteriores. No es de extrañar que el "baile" monetario continuara con su hijo Constancio II, que no sólo sobrevivió a toda su familia y libró costosas guerras contra persas, sármatas, cuados, marcomanos y alamanes, sino que tuvo que hacer frente nada menos que a seis usurpaciones, ${ }^{147}$ entre ellas la de Magnencio, que llegó a hacerse con el control de todo Occidente, y la de su primo Juliano, al que acabó nombrando sucesor en el lecho de muerte.

143 Amiano XXVI, 7, 11. Nuestra exposición se concentra en el flujo principal de la moneda, y ha pasado por alto las interesantísimas emisiones de estos usurpadores, como las de Magnencio (RIC VIII, pp. 40-3 y 63-4), Máximo y Eugenio (RIC IX, pp. xxi-v).

144 H. ELTON, Warfare..., pp. 125-7.

145 G. DEPEYROT, Crisis e inflación..., pp. 15-44, 68-80, 233-6 y 252-8. La verdad es que se ha insistido tanto en su peso aplastante que hay quien, como R.S. BAGNALL, Egypt in Late Antiquity, Princeton, 1993, pp. 153-60, se pasa por el extremo contrario y sostiene que los impuestos eran más bien leves.

146 Aparte de las impopulares subidas de impuestos y las compras obligatorias a precios inferiores a los del mercado, otros métodos para obtener recursos eran la venta de la propiedad pública y las incautaciones de bienes (G. DEPEYROT, Crisis e inflación..., pp. 45-53 y 240-3). Ya hemos mencionado la confiscación de los templos paganos (nota 117), a la que se sumó la de los bienes municipales, $c f$. A.H.M. JONES, The Later Roman Empire...,v. I, pp. 732-734. Es casi evidente que ninguna de estas vías era tan conveniente como la inflación, que, además de ser mucho más discreta que asaltos contra la propiedad privada tan brutales como los antedichos, permitía reincidir, y prueba de ello es que desde Nerón la devaluación de la moneda fue imparable a pesar de los esfuerzos en sentido contrario de emperadores moralizantes como Domiciano (81-96) o Pértinax (193).

147 Las de Magnencio y Decencio (350-3), Vetranio (350), Nepociano (350), Silvano (355) y Juliano (360-1). 


\section{CONCLUSIONES}

Sin caer en el hipercontinuismo de algunos, ${ }^{148}$ la moderna historiografía ha puesto en cuarentena el viejo tópico de la "caída del Imperio Romano" y “el fin de la civilización”, en su interpretación más dramática y tremebunda. ${ }^{149}$ Pero no por ello cabe pensar que los efectos de la inflación no fueron terriblemente perniciosos y no tuvieron mucho que ver en la crisis del siglo V. Extraemos las siguientes conclusiones:

a) La inflación es un fenómeno estrictamente monetario. El aumento de los precios es su principal consecuencia.

$\beta$ ) La inflación del siglo IV fue una política deliberada del gobierno imperial para obtener una financiación extraordinaria en momentos de necesidad acuciante.

$\gamma$ ) Existe una estrecha relación existente entre las alteraciones monetarias y los eventos bélicos.

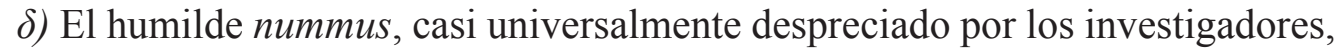
es el gran protagonista de esta crisis inflacionaria, y no el sólido áureo.

ع) Lejos de poner coto a la inflación o tener un carácter revolucionario, la reforma monetaria de Diocleciano fue continuista e institucionalizó el problema de vellón, sentando las bases de la política monetaria del siglo IV. La política monetaria de Constantino tampoco representó un viraje con respecto a la precedente, pero sí las reformas de Constancio II, Juliano y los Valentinianos.

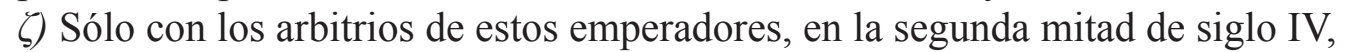
se recupera parcialmente la estabilidad, al reintroducirse un circulante medio de plata. Sin embargo, continúa la emisión inflacionaria de calderilla de cobre.

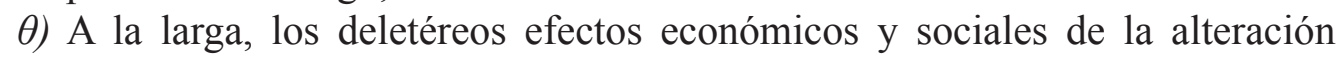
del vellón durante el siglo IV fueron catastróficos y debilitaron al Imperio, constituyendo uno de los principales factores de las transformaciones de la Roma tardía y el hundimiento del poder imperial en Occidente.

148 Pensamos en J. DURLIAT, Les finances publiques de Dioctétien aux Carolingiens (284-889), París, 1990, tan agudamente criticado por C. WICKHAM, "La caída de Roma no tendrá lugar", en L.K. LITTLE y B.H. ROSENWEIN (eds.), La Edad Media a debate, Madrid, 2003, pp. 80-101.

149 Sirvan de ejemplo E. GIBBON, The History of the Decline and Fall of the Roman Empire, Londres, 177689; A. PIGANIOL, L'Empire chretien, 325-395, París, 1947; o, más recientemente, B. WARD-PERKINS, The Fall of Rome and the End of Civilization, Oxford, 2005. 